\title{
Heritage Languages and Their Speakers: Opportunities and Challenges for Linguistics
}

\section{Citation}

Benmamoun, Elabbas, Silvina Montrul, and Maria Polinsky. 2013. Heritage Languages and Their Speakers: Opportunities and Challenges for Linguistics. Theoretical Linguistics 39, no. 3-4: 129181.

\section{Published Version}

doi:10.1515/tl-2013-0009

\section{Permanent link}

http://nrs.harvard.edu/urn-3:HUL.InstRepos:12872219

\section{Terms of Use}

This article was downloaded from Harvard University's DASH repository, and is made available under the terms and conditions applicable to Open Access Policy Articles, as set forth at http:// nrs.harvard.edu/urn-3:HUL.InstRepos:dash.current.terms-of-use\#OAP

\section{Share Your Story}

The Harvard community has made this article openly available.

Please share how this access benefits you. Submit a story.

\section{Accessibility}




\title{
Heritage Languages and Their Speakers: Opportunities and Challenges for Linguistics \\ Elabbas Benmamoun ${ }^{l}$, Silvina Montrul ${ }^{1}$, Maria Polinsky ${ }^{2}$ \\ ${ }^{1}$ University of Illinois at Urbana-Champaign \\ ${ }^{2}$ Harvard University
}

\begin{abstract}
Native speaker competence is typically the result of normal first language acquisition in a predominantly monolingual environment, with optimal and continuous exposure to the language being acquired. In this article, we discuss the case of heritage speakers: receptive bilinguals, speakers of an ethnic or immigrant minority language, whose first language does not reach native-like attainment in adulthood. We present a brief overview of the heritage speaker's linguistic system and discuss competing factors that shape this system in adulthood. We examine several theoretically relevant notions from the standpoint of their representation in heritage language (including case and interface phenomena). The connection between theory and heritage language studies underscores the potential this population offers for linguistic research.
\end{abstract}

\section{Introduction}

What do we know when we know a language? This question is at the heart of the debate about the language faculty. The usual answer is that we know a system of sounds (or gestures/signs), as well as ways of putting these sounds together in a systematic fashion to make up meaningful linguistic units. These units in turn can be, to a large extent, manipulated and combined to form more complex linguistic units, such as phrases, sentences, and extended discourse. A main bone of contention with respect to this position deals with whether the system at the core of our linguistic knowledge (i.e., what enables us to produce and comprehend linguistic stimuli) is specific to language, or whether this ability is a part of our general cognitive abilities. There is no question that within a speech community the so-called "normal" native speakers (those with no linguistic deficits who have been exposed to their native language from childhood) share 
a complex linguistic system (i.e., a grammar) that enables them to communicate with each other beyond what is allowed by an elementary system of communication shared by many species or by people who do not speak the same language, to process each other's linguistic input, and to transmit language to subsequent generations. Since the 1960s, research in linguistics has centered on how that knowledge, or "linguistic competence," develops in native speakers, as well as on the properties of the "stable" or "mature" adult system.

Native speakers of a language intuitively recognize fellow native speakers upon seeing or hearing them. To begin with, a prototypical (educated) native speaker living in a monolingual environment or if living in a bilingual one, who has not undergone attrition, has "native" pronunciation and a sizable and comprehensive vocabulary. ${ }^{1}$ Such a person speaks using grammatical sentences (except for the occasional slip of the tongue), does not omit or misplace morphemes, recognizes ambiguity and/or multiple interpretations and pragmatic implications of words and sentences, and is attuned to his or her sociolinguistic environment (social class, social context, gender, register, etc.). Such native speakers are readily accepted by members of their speech community (which can be as wide as the entire language when you are the only other speaker of German stranded in Sri Lanka, or as narrow as the jargon of a particular high school group).

\footnotetext{
${ }^{1}$ It is of course debatable whether being educated should be part of a definition of a native speaker. Although language is an oral phenomenon and writing is a cultural invention, in countries with high literacy rates, native speakers are educated, and we know that the level of education plays a role in degrees of linguistic competence in one's language (Pakulak \& Neville 2010, Dąbrowska 2012). Literacy has also been related to delaying or even sparing the process of language attrition in children (Zaretsky \& Bar-Shalom 2010). It is not clear to what extent written language helps fix the language in the mind of a native speaker. At the same time, exposure to the written register provide speakers the opportunity to expand their vocabulary and syntactic repertoire. The role of literacy, of course, raises a host of issues particularly insituations where the variety of literacy maybe significantly different from the spoken varieties (as is the case with Arabic).
} 
There seems to be a consensus that native speakers are different from non-native speakers with regard to the mastery of their linguistic system, with degrees of fluency varying according to the age of first exposure to the language. Normally developing native speakers seem to attain, for lack of a better term, relatively complete or full acquisition of their native language system, which provides them with the generative capacity to use and process their language in all its richness and complexity. ${ }^{2}$

Adult non-native speakers, on the other hand, tend to exhibit persistent signs of non-target acquisition, in areas of phonetics, phonology, inflectional morphology, semantics, syntax, and discourse/pragmatics. For example, non-native speakers may master wh-movement in English when asked to judge sentences in a grammaticality judgment task (White \& Genesee 1996). However, in spontaneous oral and written production these speakers may still continue to display problems with subject-auxiliary inversion, such as failing to consistently invert the subject and the auxiliary verb in the matrix clause, or applying inversion in subordinate clauses with indirect questions. Although some very advanced L2 speakers do not vary qualitatively from native speakers in selected grammatical domains, in general, post-puberty second language learners rarely attain complete mastery of the target language, anoutcome sets them apart from native speakers.

Native speakers and L2 learners are, however, just two extremes in a continuum of language attainment. In this paper, we discuss a different population, one that has been

\footnotetext{
2 There have been recent arguments that even apparent native speakers may not attain full mastery of some constructions (Green \& Morgan 2005; Dabrowska 1997, 2012). It is also assumed within recent work on exemplar-based approaches to language acquisition (Tomasello 2003) that language acquisition is a continuous process (i.e., that there may not be a critical period, though we are not sure that this is indeed the claim). Our main point is that regardless of whether the terms complete vs. incomplete acquisition accurately capture the dichotomy between the two types of speakers, the dichotomy exists and it is our responsibility as language scientists to account for it.
} 
claimed to share properties of both native and L2 speakers: heritage speakers. The study of heritage speakers lies at the forefront of language development in migration contexts and is relevant given recent trends in globalization and population movements across linguistic borders. Within linguistics, interest in the language of immigrants and their children has traditionally taken center stage in contact linguistics, sociolinguistics, linguistic anthropology, historical linguistics, bilingual education, and creole studies. ${ }^{3}$

Most recently, however, it has caught the attention of psycholinguistics, neurolinguistics, , and theoretical linguistics. While we welcome and embrace the rich interdisciplinary potential of heritage speakers, the purpose of this paper is to highlight the relevance of this linguistic group to theoretical linguistics, an area of linguistics that has given primacy to the "monolingual" native speaker as the most valuable source of data for linguistic theories. Such an emphasis on monolingual solid speakers was reasonable in the early stages of theory construction when the main goal was mainly to delimit the structural characteristics of the language faculty. Now that such foundational work has been done, it is important to apply and test theoretical premises on new populations. As is the case with any difficult and multidimentional problem, additional perspectives and sources of data are invaluable and sometimes can provide the missing link or critical piece of evidence.

In the following sections of the paper, we present and discuss pertinent characteristics of heritage languages and how they relate to prominent issues that touch on the nature of linguistic knowledge and its cognitive underpinnings. The paper is

\footnotetext{
${ }^{3}$ Many issues raised by the language of heritage speakers naturally intersect with research in L1 attrition, bilingual first language acquisition, and second language acquisition (see for example Montrul 2008, 2012; Sorace 200X). However, the main goal of the article and space limitations do not allow us to address these intersectiona in more detail here.
} 
structured as follows: Section 2 introduces the phenomenon of heritage speakers and their languages, with particular emphasis on the diagnostics that can be used to identify such speakers. Section 3 presents an overview of grammatical features found in heritage languages. Section 4 shows how an investigation of linguistic theory could benefit from heritage language study. Section 5 presents some considerations on the forces that shape heritage language grammar. Our conclusions appear in section 6.

\section{Heritage languages and their speakers}

\section{$2.1 \quad$ Introducing heritage speakers}

The terms heritage language and heritage speaker are fairly new, and they are still poorly understood outside of the USA, where similar concepts are denoted by the phrases minority language/speaker. Although the terms are new, the phenomenon has probably been with us as long as language contact has existed and migrations have happened. Heritage language development is a common outcome of bilingualism, where one of the languages becomes much weaker than the other. In particular, the term heritage speakers typically refers to $2^{\text {nd }}$ generation immigrants, the children of first generation immigrants, living in a bilingual environment from an early age. Unlike heritage speakers who are dominant in the language of the host country, first generation immigrants are dominant in their native language, and may or may have not undergone L1 attrition in specific aspects of their grammar.

As this paper discusses different variants of language, it is important to introduce some distinctions we will use below. First language (L1) and second language (L2) are distinguished by the temporal order of acquisition. In the case of simultaneous bilinguals, we can speak of two L1s (Meisel 2011). Critically, over the lifetime of a bilingual, one of 
the two languages typically wins over; the other language becomes somewhat weaker depending on experience, context, and degree of language use (Grosjean 2008). The next distinction we need to draw is that between the primary and the secondary languages, which are differentiated by prevalence of use. Thus, if an individual learns language A as his/her first language and speaks it predominantly throughout the adult life, that language is both first and primary. If an individual dramatically reduces the use of his/her first language $\mathrm{A}$ and language $\mathrm{B}$ becomes more dominant, then $\mathrm{A}$ is characterized as this person's first/secondary language, and B becomes the second/primary language.

Another important distinction concerns the sociopolitical status of the languages being considered. The majority language is often the language spoken by an ethnolinguistically dominant group. It has a standard, prestige, written variety used in government and media, and it is the language used as the vehicle for literacy and education imparted at school. Minority languages typically have relatively lower prestige and no or lesser official status; they may not be used beyond restricted contexts; they are not typically taught in schools, and may even lack a standardized script, limiting their literacy reach. Immigrant languages are minority languages while the societally dominant language (e.g., English in the United States) is the majority language.

Let us now tie all of these distinctions together. A heritage speaker is an early bilingual who grew up hearing and speaking the heritage language (L1) and the majority language (L2) either simultaneously or sequentially in early childhood (that is, roughly up to age 5; see Schwartz 2004, Unsworth 2005), but whose L2 became their primary language at some point during childhood (typically after the onset of schooling). As a 
result of language shift, by early adulthood a heritage speaker can be strongly dominant in the majority language.

The best-known and most widely used definition of heritage speakers is Valdés's (2000): "individuals raised in homes where a language other than English is spoken and who are to some degree bilingual in English and the heritage language." Although the original definition is English-centered, any other dominant language can be substituted for English in this definition. The crucial criterion is that the heritage language was first in the order of acquisition but was not completely acquired because of the individual's switch to another dominant language or become attrited under pressure from the dominant host language. The other critical component of this definition has to do with identifying a continuum of proficiency, reflecting the tremendous variation in heritage language ability observed by several researchers (see Polinsky \& Kagan 2007; SilvaCorvalán 1994).

\subsection{Variability in command of the heritage language}

A defining characteristic of heritage speakers is the degree of receptive and productive command of the heritage language, which varies significantly within groups and along the lifespan of each individual. Some have merely receptive knowledge of the language, while others may have near-native linguistic abilities in listening, speaking, reading and writing. It is typical of heritage speakers to have better developed listening and speaking abilities as compared to reading and writing abilities; this discrepancy is due to the lack of schooling in the heritage language (Rothman 200X). Furthermore, heritage speakers seem better at listening than at speaking, and their self-reports also 
emphasize the listening bias (Carreira and Kagan 2011). A challenge for researchers is how to evaluate the linguistic proficiency of those who fall at the lower end of the ability continuum. A variety of tests have been proposed, and they all fall into two general categories: biographical and linguistic.

\subsubsection{Biographical tests}

One diagnostic of heritage language proficiency relates to the manner and length of exposure to the baseline language. These two characteristics seem interrelated in ways that are not yet fully understood. With respect to manner of exposure, it is natural to expect that speakers who grew up surrounded by the baseline language in the homeland ${ }^{4}$ should differ in proficiency from those who grew up in an immigrant community in the U.S. or any other country where a different language is dominant. Exposure to a language in the homeland setting is inevitably greater than that in immigrant communities where bilingualism is prevalent, so one would expect, for example, a heritage Korean speaker who spent her first five years of life in Korea to have an advantage over an Americanborn Korean heritage speaker.

Au et al. (2002), Oh et al. (2003) and Au et al. (2008) show that speaking the majority language before age five puts heritage speakers at a small but measurable risk for poorer heritage language skills during adolescence. By analogy, the length of exposure to the baseline in its various contexts and registers should also matter, because the longer the exposure to the baseline, the greater the baseline input to the heritage speaker. Some studies of heritage speakers have shown that the difference between being

\footnotetext{
${ }^{4}$ Here and below we refer to the location where the immigrant language is spoken by the majority as its homeland.
} 
a simultaneous or a sequential bilingual affects the quality of the heritage grammar that results in some specific structures.

Montrul (2002) investigated morphological knowledge and semantic interpretations of preterite and imperfect tenses in Spanish and found that the heritage speakers living in the US who were exposed to Spanish and English since birth had a more divergent system of Spanish aspectual contrasts than the sequential bilinguals; both groups however were different from the baseline. Meanwhile, a group of late child L2 learners (exposed to Spanish exclusively until ages 8 to 12 when they moved to the United States) were no different from the adult native speaker baseline. These results show that the effects of context and length of exposure are not easily separable. The only group that seems to have a distinct language advantage is heritage speakers who grew up in the monolingual environment of the baseline language and had exposure to the baseline language between the ages of $8-12$, before the closure of a critical/sensitive period for L2 acquisition and L1 attrition. This finding is significant in light of two recent studies that have argued that puberty is a critical age for both the acquisition of a second language and the loss of a first language in a bilingual environment (Bylund 2009, Montrul 2008).

Of course, the quality of the input during childhood, not just the quantity, have been shown to matter as well in the grammatical development of simultaneous and sequential bilingual children (Unsworth et al. in press). In a recent study, Montrul (2013) found no differences between heritage speakers of Spanish and first generation Mexican and Latin American immigrants to the US in their production of dative case and diffrential object marking, but the three US groups were significantly less accurate than 
SES and education-matched native speakers in Mexico. This study suggests that incomplete acquisition in some heritage speakers can also be exacerbated by attrition in the first generation, who are the main source of input to the heriutage speakers. However, this observation does not apply to all heritage languages. Montrul (2013) also included first generation and $2^{\text {nd }}$ generation Hindi and Romanian immigrants to the US as well as age and SES-matched Hindi and Romanian speakers in India and Romania. The findings revealed incomplete acquisition (or attrition) in the Hindi and Romanian heritage speakers, but the first generation immigrants scored on all measures significantly higher than the heritage speakers and were no different from the native speakers in India and Romania. Thus it is not always the case that first generation immigrants show signs of attrition.

A common characteristic shared by many (though not all) heritage speakers has to do with limited, and in many cases no, of literacy in the heritage language. This deficit is relevant only for those languages that have a literary and schooling tradition - a heritage speaker of Seneca who grew up on a reservation in the US in the early twentieth century had no recourse to literacy. For heritage speakers of languages such as Korean, Persian, Arabic, Russian, or Swahili, absent or insufficient schooling outside of the homeland creates a much greater divide between them and their peers in Korea, Iran, Egypt, Russia, or Kenya. Moreover, for some languages, such as the spoken colloquial dialects of Arabic, there is a lack or scarcity of written media, which exists predominantly in a formal variety that is significantly different from the spoken forms (Ferguson 1979, Walters 1996, Versteegh 2001). The effect of literacy on language proficiency has been 
the subject of intense scrutiny in recent literature, and the bottom line is unsurprising: literacy aids language maintenance and retention (Kondo-Brown 2009; Delgado 2009, Zaretsky \& Bar-Shalom, 2010, Rothman 2007, Pires \& Rothman 2009). However, there are different ways of developing literacy, and not all of them may be equally effective.

\subsubsection{Language-based diagnostics}

Recent research on heritage languages has also focused on identifying purely linguistic diagnostics that allow us to measure a heritage speaker's knowledge of their home language and possible proximity to the baseline. Although the progress made in this area has been quite modest, several promising diagnostics have emerged. One of the most important ones seems to be speech rate (Polinsky 2008b, 2011).

Speech rate can be measured as the word-per-minute output in spontaneous production. A speaker can be asked to describe one set of pictures in their heritage language and another set in their primary and dominant language; doing so provides a standard of comparison for assessing individual variation in speech rate. Results show that a heritage speaker's speech rate may be as low as $30 \%$ of the speech rate of full speakers of the same language (baseline).

The relevance of speech rate is attested by a study of gender restructuring in heritage Russian (Polinsky 2008b), which showed that heritage speakers fell into two distinct groups: those who maintained the baseline three-gender system of noun classification with various adjustments, and those who radically reanalyzed the baseline system as a two-gender system. Reanalysis of the baseline three-gender system as a twogender system was strongly correlated with a lower speech rate, thus supporting the use 
of speech rate as a reliable diagnostic for measuring the fluency of heritage speakers and tracking the variation in the population. The source of the correlation between speech rate and degree of grammatical knowledge is straightforward: lower proficiency speakers have more difficulty in accessing lexical items, which slows down their speech, but also significantly compromise comprehension and use of structure types that require quick incremental integration of information. In addition, speech rate is connected to utterance planning, and lower proficiency speakers have more problems in that domain as well. Spontaneous speech is thus punctuated by pauses, repetitions, false starts, and codeswitching. As we will show below, knowledge of lexical items and grammatical knowledge are also correlated.

While speech rate may be a promising method of identifying and classifying heritage speakers, it may be difficult to calculate in the lowest-proficiency heritage speakers, who are often reluctant to produce spontaneous speech. Another diagnostic which has the potential to avoid this issue of speaking reluctance is lexical proficiency. Polinsky (1997, 2000, 2006) and O’Grady et al. (2009) observed a strong correlation between a speaker's knowledge of lexical items, measured in terms of a basic word list (about two hundred items), and the speaker's control of grammatical phenomena such as agreement, case marking, aspectual and temporal marking, pro-drop, co-reference, and embedding. Grammatical knowledge was measured by deviations from the baseline in spontaneous speech (Polinsky 1997) and, in later studies, by answers to forced-choice judgments (Polinsky 2005, 2008b, 2011). The correlation between grammatical and lexical knowledge was supported by results from several heritage languages, including Arabic, Russian, Polish, Armenian, Korean, and Lithuanian (see also Godson 2003, 
Albirini \& Benmamoun, in press, a.o.). This relationship between grammatical and lexical knowledge is not exclusive to heritage language competence; it has also been proposed for early child language (Fenson et al. 1994; Thal et al. 1996, 1997). If structural attrition and lexical proficiency are correlated, lexical proficiency scores, which are relatively easy to obtain, can serve as a basis for the characterization and ranking of speakers with incomplete development of their heritage language.

We have discussed only two approaches to identifying heritage speakers' proficiency here, and we would like to underscore the importance of proper tools for rating heritage speakers. Such tools are needed because of the noticeable variation among heritage speakers. In addition, as experimentation becomes an increasingly important tool in modeling the development and end-state of linguistic knowledge, considerations of effective experimental design have become necessary parts of critical review. Findings based on questionable methodology can have far-reaching effects, not only by slowing the theoretical advancement of the field, but also by stagnating the content and pedagogy of language instruction.

\section{The Grammatical System of Heritage Language Speakers at a Glance}

\subsection{Sound systems}

\subsubsection{Existing studies of phonetic and phonological skills}

Phonological competence seems to be the best preserved aspect of linguistic knowledge in heritage speakers. Nevertheless, it is affected in heritage language as well. With respect to production, Au et al. (2002), Oh et al. (2003), and Knigthly et al. (2003) show that low proficiency Spanish and Korean heritage speakers have more non-native 
accents than native speakers in general, suggesting that pronunciation is affected in heritage speakers to some extent. The differential effects depend on the particular phonemes; for instance, Au et al. (2002) demonstrate that low proficiency Spanish heritage speakers showed no differences in their productions of the VOTs of voiceless stops when compared with native speakers. Oh et al. (2003) show that even low proficiency Korean speakers had unimpeded phoneme perception.

Godson (2004) documents phonetic changes in vowel production in Western Armenian heritage speakers living in the United States. Godson found that the heritage speakers retained the 5-vowel system of Western Armenian in production, but the two front vowels $/ \mathrm{i} /$ and $/ \varepsilon /$ and the central vowel /a/ differed in quality from those produced by native speakers. Unsurprisingly, the quality of these vowels was similar to their counterparts in English. Therefore, while heritage speakers retain their native phonology, the phonetic values of both vowels and consonants are affected, thus contributing to a 'heritage' accent. Another striking feature of heritage speakers examined by Godson has to do with the leveling of dialectal differences as compared to the baseline. Western Armenian is a language of the Armenian diaspora, associated with a variety of dialects dispersed in the Middle East. As compared to the baseline, heritage speakers of Western Armenian all sound much more alike, an informal observation that Godson was able to support by quantitative measures. To date, the pronunciation of heritage speakers remains an understudied area. Nonetheless phonological retention is relatively high among heritage speakers when compared with various other aspects of their grammar. Crucially, heritage speakers outperform native-like L2 speakers although sometimes it takes sensitive methodology to uncover the differences. Abrahamsson and 
Hyltenstam (2009) studied highly fluent L2 speakers and their skills across multiple domains of language using highly sensitive tests and found that native-like fluency is not the same as native fluency. In particular, studies of voice onset time revealed that at higher levels of resolution, fluent non-native speakers do not pass for native speakers. Thus apparent native-like L2 fluency achieved in adulthood is not as robust as native fluency.

With respect to comprehension, the main finding seems to be that phoneme differentiation is generally quite strong. For example, Oh et al. (2003) show that even low proficiency Korean speakers had unimpeded phoneme perception. Again, there is initial evidence that heritage speakers outperform highly fluent L2 speakers. For instance, Sebastian-Galles and Soto-Faraco (1999) tested L2 Catalan speakers with L1 Spanish speakers; such speakers, however fluent, performed worse in discriminating Catalan phonemic contrasts than native Catalan speakers.

Phonological discrimination is an important area where studies of low proficiency heritage speakers can inform our hypotheses concerning critical or sensitive period (Newport 1990). ${ }^{5}$

\subsubsection{Heritage language phonology and critical period effects}

Let's start with some basic assumptions. It is relatively uncontroversial that young children's acquisition of their L1 phonology is completed by around 12 months (REF). The acquisition of phonology and word-learning are interdependent; the acquisition of lexical items is dependent on a sufficient acquisition of phonology, and the phonology is honed by the patterns discerned in the words learned (Werker and Tees 2005). Such

\footnotetext{
${ }^{5}$ The literature on critical period is enormous and it is beyond our goals to represent it here, so we will limit ourselves to just a subset of relevant references.
} 
interdependence underlies the model of optimal periods where the acquisition of a certain domain serves as part of the foundation for the next one, and the whole process begins with the honing of acoustic and then phonetic sensitivity, triggering a cascade of the opening and closing of the optimal periods. Taken together, the collection of optimal periods constitutes the critical or sensitive period, which begins with the onset of the first optimal period (acoustic sensitivity) and ends with the offset of the final optimal period (presumably a higher-level domain such as syntax. However, since neither the onset nor the offset of any optimal period is invariant according to Werker and Tees (2005), this window of sensitivity is not absolute, and it should allow for some flexibility regarding age of onset of acquisition.

Complementary to the system of optimal periods determining the specific, concrete trajectory of L1-acquisition is the Native Language Neural Commitment (henceforth NLNC) hypothesis developed by Kuhl et al. (2005). According to this hypothesis, early experience in the native language promotes its own acquisition by making sensitivity increasingly more specific to the native language, and, by the same token, inhibits language learning that is unrelated to it. The hypothesis postulates that cognitive resources are limited and that as the child is exposed more and more to a language, establishing it as the native language, these resources are committed to the native language in steps. Kuhl et al. 2005 show a negative correlation between the ability to discriminate native phonemes and the ability to discriminate non-native phonemes at 7 months of age, indicating that as native language ability increased, ability in non-native languages simultaneously decreased. Children with higher perceptual skills in the native language at 7 months also showed stronger performance in word production, sentence 
complexity, and other higher domains of language at 18 and 24 months, while children with greater perceptual ability in non-native languages showed lesser ability in the higher domains of the native language at these older ages. According to the NLNC hypothesis, this is brought about by a difference in the amount of commitment to the native language between these children: worse performance on non-native contrasts reflects a more complete monopolization of cognitive resources by L1, which also explains the more advanced ability in higher-level domains of L1. After 24 months the differences in higher-level L1 ability were reduced (p. 248); by this point, the L1-commitment of the children who had performed better on non-native contrasts had presumably caught up to that of the children who performed better on native contrasts.

The NLNC hypothesis posits that once commitment is complete, the fundamental, underlying rules of the language are solidified in the mind so that learning is no longer needed, and the sensitive period closes. Once an underlying understanding of the rules of a language is sufficiently established, the flexibility is no longer necessary, and the window of sensitivity can close; this is neural commitment to the native language in its completed form. However, only when all of the domains have been acquired, and thus all the optimal periods have closed, can the sensitive period as a whole close.

Assuming the framework of optimal periods and the NLNC, what happens in sequential bilinguals? The commitment to L1 has already been made, so the ability of to learn a new native language after exposure to L1 could result from a reorganization of the cognitive resources at the expense of the original native language, prolonging (or renewing) access to the optimal periods that normally close once the relevant commitment is complete. Two possibilities offer themselves. Under one option, the 
commitment effects of the NLNC are irreversible; once commitment has taken place in each optimal period, the resources dedicated to the original language cannot be reassigned, and the knowledge persists throughout life. Under the alternative, the persistence of learning is contingent upon continued exposure to the language; if this input ceases, reorganization of the resources can occur, optimizing the neural system to another language. This reorganization is more likely early in life, before commitment is stabilized with the closing of the sensitive period. Thus:

(1) Permanence hypothesis: once commitment has taken place in each optimal period, the resources dedicated to the original language cannot be reassigned, and the relevant knowledge persists throughout life

(2) Contingency hypothesis: the persistence of learning is contingent upon continued exposure to the language; if this input ceases, reorganization of the resources can occur, optimizing the neural system to another language

(Brenner 2010: 9-13)

It is clear that heritage speakers offer an unprecedented opportunity to test the two hypotheses, and no other cases are as helpful for testing them as the case of early international adoptees or overhearers whose exposure to their L1 was limited in childhood.

Pallier et al. (2003) tested the L1 abilities of Korean adoptees in France. The subjects in their study ranged in age from 20 to 32 at the time of testing, and were adopted between 3 and 8. They reported no remaining conscious ability in Korean and were fluent in French with no perceptible accent. In the sound-discrimination test, subjects listened to 60 sentences in French, Korean, and two unfamiliar languages. They were unable to distinguish between Korean 
and unfamiliar language sentences, and their overall results were not significantly different from the results of the control group of native French subjects. This suggested that any ability to recognize the sounds of Korean that the adoptees had acquired during childhood was gone. On the second test, in which subjects attempted to match the meaning of a written French word to one of two spoken Korean words, their performance was also not significantly different from that of the native French subjects. A second study (Ventureyra et al. 2004) investigated the ability of adult Korean adoptees brought into French-speaking families between 3 and 9 years of age to discriminate Korean consonant contrasts. The adoptees performed no better than monolingual French speakers. Both of these studies offer support in favor of the Contingency hypothesis (2) and argue against the permanence hypothesis (1).

However the empirical facts are more nuanced, suggesting that the choice between (1) and (2) may not be a matter of simple choice. Bowers et al. (2009) recruited native English speakers who had substantial exposure to Hindi or Zulu as children to try to discriminate phonemic contrasts in these languages that are opaque to native English speakers. Both groups performed as poorly as an English-speaking control group on a vocabulary test in either Hindi or Zulu, indicating that they had no remaining conscious knowledge of these languages.

The subjects were given the AX task: one hears two sounds and determines whether they are the same or different (whether X is like A). After 30 trials of $112 \mathrm{AX}$ tests divided between Hindi and Zulu, all three of the subjects under 40 years of age had achieved near-native performance on the contrasts of their respective forgotten languages; at the same time, they showed no improvement in the other language (the one 
with which they had had no prior experience). The subjects older than 40 , however, showed no more improvement than the control group. The authors note attribute the difference to the possibility that the longer one is isolated from the forgotten language, the more the latent ability atrophies. It is also possible that older subjects simply show a much greater decline in re-learning.

The subjects who did improve only improved in distinguishing sounds of the language with which they had had experience; thus Hindi-oriented subjects improved on Hindi but not on Zulu sounds. This suggests that the improvement was not simply a case of across-the-board learning, but rather could have been an activation of latent, previously inaccessible ability in the forgotten language. The dental/retroflex contrast in Hindi and the plosive/implosive contrast in Zulu are both non-phonemic in English, and in both cases the contrasts would be subsumed into a single phoneme in English. Therefore, the successful participants show evidence of a phonemic contrast that would have been overwritten by an allomorphic one in the case of complete reorganization, thus supporting the permanence hypothesis (1).

Oh et al. (2010) is another study in support of the permanence hypothesis. The authors recruited 25 college students in the second week of an introductory Korean class, 12 of whom were adoptees (age of adoption ranging from 12 to 33 months); the remaining 13 served as native-English controls. Simplifying things somewhat, the adoptees clearly outperformed the control group in their ability to distinguish a threeway, lenis-tense-aspirated phonemic contrast in Korean. The persistence of phonological ability in two studies suggests, that even when reorganization occurs, it may be incomplete. 
The factor that could reconcile the findings is re-exposure to the original language, through either previous personal experience or experimental methods. The two studies that showed evidence of latent ability incorporated a form of re-exposure into the method: Bowers et al. (2009) repeated sessions of 112 trials 30 times with their subjects, and Oh et al. (2010) recruited participants from a beginning Korean class. On the other hand, Pallier et al. (2003) and Ventureyra et al. (2004) both tested subjects without requiring or providing re-exposure. What is striking is that the re-exposure was quite minimal, especially in the Oh et al. (2010) study. This in turn suggests that re-exposure may serve as a triggering experience for accessing latent knowledge. We do not have all the answers but it is tempting to offer a metaphor here: the language that was not accessed for a while is like an abandoned road, which is covered with some debris but not lost. The re-exposure does not build a new road but cleans the old one, opening up the forgotten pathway.

\subsection{Morphology}

\subsubsection{Non-isolating languages}

The sub-module of language that is most affected and more prone to variability in heritage speakers is inflectional morphology in languages that exhibit morphological systems and regular and irregular paradigms. In languages such as Arabic with root and pattern morphology (McCarthy 1979), other issues arise that concern knowledge of the notion of a root and the mapping mechanisms for linking the root and the vocal melody to the template. Benmamoun et al. (in press) and Albirini \& Benmamoun (2012) report that heritage speakers have incomplete knowledge of the notion of a root (particularly roots 
that contain glides and geminate consonants). Unlike native speakers, heritage Arabic speakers struggle with word formation processes that require access to sub-word prosodic categories such as syllables and feet. They do better on concatenative processes that affix morphemes to stems than on non-concatenative processes that require decomposing the stem into smaller prosodic units. This implies that concatenative and non-concatenative derivations are different with regard to their degrees of acquisition difficulty and vulnerability to attrition, a finding that is consistent with research on the acquisition of Arabic morphology (Omar 1973, Ravid and Farah 1999)

In the nominal domain, heritage speakers exhibit errors with gender agreement in Russian, Spanish and Swedish (Håkansson 1995, Montrul et al. 2008, Polinsky 2008b), definiteness agreement in Swedish and Hungarian (Håkansson 1995, Bolonyai 2007), case marking in Russian and Korean (Polinsky 1997, 2006, 2008a, b, Song et al. 1997), and concord in Arabic (Albirini et al. in press). Similar patterns of erosion are attested in the verbal domain, including agreement in Russian (Polinsky 1997, 2006), lexical aspect in Russian (Pereltsvaig 2005; Polinsky 1997, 2006, 2011), grammatical aspect in Spanish and Hungarian (Montrul 2002, Fenyvesi 2000, de Groot 2005), mood in Spanish, Russian, and Hungarian (Lynch 1999, Montrul 2009, Silva-Corvalán 1994, Polinsky 1997, 2006, Fenyvesi 2000), and inflected infinitives in Brazilian Portuguese (Rothman 2007).

Morphological deficits in heritage languages are asymmetric; they are more pronounced and pervasive in nominal morphology than in verbal morphology (see Bolonyai 2007 for the same observation), and within verbal morphology, deficits seem to target a subset of categories. One example of such a nominal-verbal morphological 
asymmetry comes from Hindi heritage speakers, who make case-marking errors in the range of 23-27\%, while their verbal agreement errors are under 7\% (Montrul et al. 2012). Low-proficiency heritage speakers of Russian have an error rate of about $40 \%$ in their nominal morphology, and fewer than $20 \%$ in their verbal agreement morphology. Observations on production in heritage Hungarian (Fenyvesi 2000, de Groot 2005), including the Hungarian of English-dominant bilingual children (Bolonyai 2007), also point to significant attrition of nominal morphology (omission of case affixes and the possessive suffix; overextension of definite forms) despite well-preserved verbal morphology, including agreement marking on verbs. Within verbal agreement, the forms which are affected the most are those with object agreement (Bolonyai 2007; Fenyvesi 2000).

Albirini et al. (in press) report that Egyptian and Palestinian heritage speakers display better command of subject-verb agreement compared to noun-adjective agreement or concord. Their accuracy rate on subject-verb agreement in production stood at $82.78 \%$ as compared to a $63.92 \%$ accuracy rate for adjective-noun agreement (concord). This finding is intriguing despite the fact that the verbal agreement paradigms are significantly larger than adjectival paradigms and hence possibly more costly to acquire. However, the centrality of verbs to sentential syntax may outweigh the relative morphological simplicity of adjectives, and thus facilitate the upkeep of these verbal paradigms in the heritage grammar.

Within the verbal morphological complex, there seems to be a further asymmetry regarding categorical features. Tense marking is unaffected and there are no reports of tense errors in heritage grammars (Fenyvesi 2000). However, in addition to agreement 
marking, which is generally affected, heritage speakers commonly make errors in aspectual morphology (Montrul 2002, 2009, Polinsky 2006, 2008c, de Groot 2005), as well as the morphology associated with mood, polarity, and possibly negation.

The data amassed so far are in need of further verification, both for the heritage languages that have been studied and for those that are still awaiting research. The emerging asymmetries are intriguing and call for an explanation. One possible explanation for the asymmetry in competency with nominal and verbal morphology may have to do with differences in the nature of these two morphologies. Some researchers have argued that nominal morphology is post- or extra-syntactic, whereas verbal morphology is directly reflexive of syntactic structure (cf. Bobaljik \& Branigan 2006, Bobaljik 2008). If so, it is possible that heritage speakers retain the syntactic ability of forming predication relations and recursive structures (the essential properties of narrow syntax) but have a reduced capacity for post-syntactic operations. If that's the case an explanation for the difficulty may be sought in two domains: interfaces (the interface between morphology and syntax and between phonology and morphology), or the division of labor between narrow syntax and post-syntactic operations which are subject to greater variation than the narrow syntax.

\subsubsection{Languages with isolating morphology}

\subsection{Lexical categories}

Every so often some linguists find examples of languages that seem to lack a noun-verb distinction (see Broschart 1997, Gil 2000 for some recent examples), and other linguists 
refute their conjectures, essentially by saying that in those languages the noun-verb distinction may be less evident (cf. Lander \& Testelets 2006; Arkadiev et al. 2009). The noun-verb distinction seems to be one of the tenets of Universal Grammar, assumed to be available to the child in order to posit a difference between nouns and verbs whenever presented with linguistic data. The fundamental noun-verb distinction may be due to the separate cognitive processes of (i) referring and labeling (nouns), and (ii) predicating, i.e., attributing properties to things (verbs) (Williams 1980, Bowers 1993, Baker 2003, Hornstein 2009, a.o.). Examining heritage speakers' knowledge of these basic lexical categories is important because it can either provide additional evidence in support of the noun-verb distinction or help refute this distinction, by suggesting that it is less fundamental than many researchers think.

Simple lexical decision studies involving heritage speakers seem to give credence to the universality of the noun-verb distinction. Polinsky (2005) and Lee et al. (2012) have shown that heritage speakers of Russian and Korean exhibit higher accuracy and response rates with verbs than with nouns. These studies show that the basic noun-verb distinction seems to hold well even in grammars that have not reached full development. More importantly, we would like to underscore that this is just one of many instances where an investigation of heritage grammars may yield results that are of value to the field in general, specifically with regard to theory construction. In the next section, we will review other findings that are theoretically significant, including some that raise new challenges for existing theories of grammar.

\subsection{Syntax}


Syntactic knowledge appears to be more resilient to incomplete acquisition under reduced input conditions than inflectional morphology. There is a tendency of heritage language grammars to keep the basic, perhaps universal, core structural properties of their language. Aspects of syntax that involve recursion and higher projections of the CP layer (i.e., complex syntax) appear to be much less productive and developed in these speakers (see Laleko 2010 for a detailed discussion). In the word order domain, Håkansson (1995) showed that Swedish heritage speakers have native-speaker control of the V2 phenomenon in Swedish, including native command of structural (or stylistic) variability with verb placement. We do not know, however, whether heritage speakers of Swedish master the full pragmatics of embedded V2. Montrul (2005) shows that even low proficiency Spanish heritage speakers know the syntactic constraints on unaccusativity in their language. However, they showed reduced sensitivity to the subtle lexical-semantic constraints that determine the categorical or gradient compatibility of individual verbs in particular unaccusative/unergative configurations. Polinsky (1997) demonstrates that the overt pronominal system of Russian heritage speakers seems to be quite resilient to incomplete acquisition. Montrul et al. (2008b) investigated knowledge of wh-movement, subject verb inversion and the that-t phenomenon in Spanish heritage speakers. They found that although there were significant differences between native and heritage speakers with object and subject extractions, the heritage speakers were quite accurate with subject-verb inversion and complementizers (that-t effect), even though Spanish and English differ in this regard.

Null pronominals, however, seem to be significantly affected in heritage grammars: heritage languages whose baseline is pro-drop are reported to lose this feature 
or to use it in a more limited manner-for example, in Hungarian (de Groot 2005), Hindi (Mahajan 2009), Tamil and Kabardian (Polinsky 1997), Spanish (Silva-Corvalán 1994, Montrul 2004), Polish (Polinsky 1997), and Arabic (Albirini et al. 2011). Sorace, who also finds a more restricted use of null pronominals in émigré languages (Sorace 2004) (i.e., the first generation speakers who are the input to the heritage speakers), attributes the difficulty to the attrition of phenomena that lie at the syntax-discourse interface. If this explanation is on the right track, one would want to ask what types of interface phenomena are prone to change under contact. It is crucial to determine whether other interfaces are also affected — below, we will address both the morphology/phonology interface and the syntax/pragmatics interface (Montrul 2011, Montrul \& Polinsky 2011).

An alternative explanation for the loss of pro-drop may stem from the observation that heritage speakers have a general difficulty in establishing and processing dependencies, especially when the dependency is at a distance. A null pronominal is always an element that has to be licensed and identified (Rizzi 1986); thus, the licensing and co-indexation of a null pronominal with a DP at a distance may cause significant difficulty in heritage grammars.

Difficulties in creating and maintaining a dependency also arise with respect to binding, which accounts for difficulties in the interpretations of anaphors by heritage speakers. This is consistent with the idea that finer details of interface construal may be vulnerabke in heritage languages. The difficulty may vary across heritage languages or across proficiency levels, or across both. Kim et al. $(2009,2010)$ show that Korean heritage speakers still retain control of the syntactic properties that license local and long distance anaphors in their language. However, Polinsky (2006) finds that heritage 
speakers of Russian often produce the correct anaphors but have significant problems interpreting binding domains. In terms of cross-linguistic differences, note that Korean caki has distinct logophoric properties (Sells 1987, Yoon 1989) that may aid in its interpretation, whereas Russian sebja is clause-bound - this parametric divergence may cause the difference in performance across heritage speakers of these languages.

Little is known about the ability of heritage speakers to deal with A-movement and A-bar phenomena. With respect to A-movement, Polinsky (2009) compared Englishdominant heritage speakers of Russian to age-matched monolingual Russian controls in a sentence-picture matching task. Subjects matched pictures to active/passive constructions, with verb-initial and verb-medial orders in Russian:

(3)
a. morjak spas pirat-a (Active SVO)
sailor.NOM saved pirate-ACC
b. spas pirat-a morjak (Active VOS)
c. $\operatorname{spas}$ morjak pirat-a (Active VSO)

'The sailor saved the pirate.'

(4) a. pirat spas-en morjak-om (Passive SVO)

pirate.NOM saved-PASS sailor-INSTR

b. spasen morjak-om pirat (Passive VOS)

c. spasen pirat morjak-om (Passive VSO)

'The pirate is saved by the sailor.'

The results show that heritage speakers have serious problems when the word order is different from SVO, regardless of voice; they also have problems with the passive. At first glance, these results seem parallel to the results obtained for child language (see 
Orfitelli 2012, Crawford 2012 for overviews) and aphasics (see Caramazza et al. 2001, Drai et al. 2001 for a full range of debate concerning the representation of passives in aphasia).

Language acquisition accounts that follow the structural theories of adult language processing, i.e., that passives and scrambled sentences are derived via movement, explain children's difficulties with these constructions as resulting from their inability to form and maintain syntactic chains (cf. the A-chain maturation hypothesis by Borer \& Wexler 1987) or to transmit theta-roles (Fox \& Grodzinsky 1998). Constraintsatisfaction accounts ascribe children's difficulties with passives to the relative paucity of this construction in child-directed speech, to the lack of appropriate discourse contexts (Otsu 1994), and, recently, to the ignoring of grammatical case markers (cf. Murasugi \& Kawamura 2005 who mainly appeal to this deficit with respect to word order disambiguation). Aphasia patients are another population that has difficulties with Adependencies (Drai \& Grodzinsky 2006).

When tested in their dominant language, heritage speakers do not show any problems with passives, which means that they certainly have A-chains in their dominant language (assuming a movement or chain-based analysis of passives). That heritage speakers command A-chains in their dominant language casts doubt on the purely syntactic explanation for their problems with the passive. If heritage speakers have access to the relevant functional projection, then their poor performance on passives may stem from the same processing strategies that have been identified in child language speakers: failure to pay attention to the relevant inflectional morphology (cf. Murasugi \& Kawamura 2005 for L1) and subsequent shallow processing that relies on some kind of a 
canonical sentence strategy (e.g., 'Interpret the first NP as agent and the second NP as patient'; cf. Hayashibe 1975 and O'Grady 1997 for L1).

With respect to A-bar phenomena, heritage speakers of Russian and Korean show difficulties in the comprehension of relative clauses (see O'Grady et al. 2001 for Korean, Polinsky 2011 for Russian), especially object relatives. Sánchez-Walker (2012), however, found that heritage speakers of Spanish do not have difficulty comprehending relative clauses in Spanish. Again, one could account for this deficit without relying on the hard to maintain notion that heritage speakers lack relevant syntactic operations; instead, problems with relative clauses may follow from poor command of morphology, specifically case morphology.

Case marking seems a particularly vulnerable domain in heritage grammars; however, it is unclear whether the problem lies with the syntactic mechanism of case licensing or with morphological, arguably post-syntactic case marking. We return to this issue in the next section.

\subsection{Semantics}

While most of the existing work on heritage language grammars has centered on the areas of morphology and syntax, there is an emerging indication that certain aspects of semantics are also highly affected in these grammars. One such area is semanticallybased, or inherent case. Polinsky $(1997,2006)$ discusses the erosion of the Russian genitive of negation, which is learned late in L1 acquisition and is generally quite 
infrequent. Similar erosion has been documented in Spanish (Montrul 2004, Montrul \& Bowles 2009, 2010). Spanish does not have a genitive of negation, but it does have differential object marking (DOM) with animate, specific direct objects, as well as differential subject marking (DSM) with dative subjects of psychological predicates. According to recent analyses, both phenomena are instances of inherent case. Spanish heritage speakers tend to omit these case markers, which happen to be the preposition $a$ in both cases. Interestingly, the preposition $a$, which is also the dative marker in prototypical dative constructions, is not omitted by heritage speakers with indirect objects. This suggests that inherent case marking may be more affected than structural case marking. DOM and ergative case marking are also degraded in Hindi heritage speakers (Montrul et al. 2012; see the discussion in section 4.1 below).

Another problematic area of emerging interest is the semantics of articles. Montrul \& Ionin $(2010,2012)$ have found that Spanish heritage speakers have a strong tendency to use bare nouns with generic reference in subject position (these are ungrammatical in Spanish but grammatical in English), and a similar tendency was found in the Italian of Italian-English bilingual children growing up in the UK (Serratrice et al. 2009). Heritage speakers of Spanish also tend to interpret definite articles in Spanish as specific in generic contexts. Although both Spanish and English have definite and indefinite articles, the languages vary in their semantic interpretations of these features. For example, genericity in English is expressed through bare plural noun phrases, as in (3a). With the definite article, (3b), the sentence refers to a specific group of tigers. In Spanish, bare plurals in subject position are typically ungrammatical, as in (4a), but the definite article can be used to express both a generic statement and a specific statement. 
So, sentence ( $4 b)$ can be a generic statement about tigers, or it can express a property of a specific group of tigers.

(5) a. Tigers eat meat.

b. The tigers eat meat.
GENERIC

SPECIFIC

(6) a. *Tigres comen carne.

b. Los tigres comen carne. $\quad$ GENERIC, SPECIFIC

Montrul and Ionin asked whether Spanish heritage speakers would tend to interpret definite plural determiners as generic, as native speakers do, or as specific due to transfer from English. Results of an acceptability judgment task and a truth value judgment task in English showed that the heritage speakers of Spanish accepted bare plurals with generic reference and definite articles with specific reference in English and were indistinguishable from a native English speaker group. But when given the same tests in Spanish, there were significant differences between the Spanish native speakers and the heritage speakers. L2 Spanish learners and the heritage speakers did not differ from each other, and, unlike the native speakers who preferred a generic interpretation for plural definites, they showed a preference for specific readings instead. Thus, in this regard, both L2 learners and heritage speakers exhibited influence from English in the interpretation of definite articles in Spanish.

\section{The relevance of heritage languages to theoretical linguistics}

Let's step away from heritage languages for a moment and ask ourselves what made first language acquisition so valuable to theoretical linguists of all persuasions. The answer seems to go like this: child language informs the debate about the role of nature 
and the role of nurture in language development. At the same time, it has less irregularity than adult language; it is less encumbered by external linguistic experience, and, therefore, it allows researchers to see more clearly how the rules and constraints operating in natural language develop. When a child over-generalizes, the mistakes are not arbitrary, as s/he draws on fundamental principles of natural language design. The same applies to errors of all types, which is why utterances like (5) never occur (Crain \& Nakayama 1987, Legate \& Yang 2002):

(7) *Is the woman who singing is happy?

There is great value in studying how language unfolds in young children, as much has been learned from this perspective about the structure of language. At the same time, we see tremendous value in studying what happens when language development regresses or does not reach its fullest potential as a result of differential input conditions or pressures from the dominant host language in an immigrant contexts.In what follows, we highlight just a few areas in which data from heritage language has a bearing on linguistic theory.

\subsection{Structural vs. inherent case}

Much of the work in applied and experimental paradigms rely on theoretical predictions to generate and test hypotheses; it is common for experimental work to establish certain generalizations in support of a particular finding in the theoretical literature. The emerging experimental work on heritage languages is no exception, but we would like to underscore that the interaction between theory and experimentation does not have to be a one-way street. It is also desirable to use experimental results as a way of feeding back into theory and challenging it on various grounds. Since heritage speakers represent a vast and readily available group of subjects that can be tested, it makes particular sense to 
think of innovative ways in which they can help researchers find new data. These data could then feed back into linguistic theory and help to promote its progress. Here we present just one example of how the data obtained from heritage speakers can provide new empirical grounds for linguistic theory. The example we chose comes from case assignment.

Case assignment theories have long distinguished at least two types of cases, structural and inherent. As its name implies, a structural case is one that is assigned in a certain structural configuration and is not dependent on the semantics of the caseassigning head. With respect to verbal case assignment, this means that the particular theta-roles in the verb's argument structure do not affect the case of the noun phrases that express the arguments. A two-place verb may take as its internal argument a theme, an instrument, a location, or a stimulus, but these arguments are all encoded in the accusative, as in English:
a. break the window (=Theme)
b. $\quad$ bake bread (=Theme)
c. $\quad$ play the guitar (=Instrument)
d. occupy Zuccoti Park (=Location)
e. admire the view (=Stimulus)

At the opposite extreme, we find inherent cases, whose assignment depends on thetamarking by the verb; thus, one could think of such cases as reflecting the argument structure of the verb directly. Usually genitive, dative, and partitive are considered 
inherent cases. In a number of languages, the case of an experiencer in subject position is dative rather than nominative, reflecting the theta-marking. Compare in Spanish:

a. Juan practica la guitarra
Juan.NOM practices the guitar
'Juan practices playing the guitar.'
b. A Juan le gusta la guitarra
DAT Juan DAT.CL. likes the guitar
'Juan likes the guitar.'

There are a number of strong syntactic arguments for this distinction between structural and inherent case, ${ }^{6}$ many of them based on English (for example, the assignment of case by a noun to its argument is inherent, cf. 1986).

Inherent case is considered "stronger" in that it is more tightly connected to its licensing expression. This in turn implies that such a case cannot be changed under displacement or nominalization. One of the best-known instances of such case preservation is the maintenance of the dative under raising, as in Icelandic. In (9), the dative experiencer, which is the syntactic subject, undergoes raising:

$\begin{array}{llccc}\text { Dómurunum }_{\mathrm{i}} & \text { virtist } \mathrm{t}_{\mathrm{i}} \text { kona } & \text { hafa } & \text { skrifað } & \text { bókina. } \\ \text { judges.DET.DAT } & \text { seemed } & \text { woman.NOM have.INF } & \text { written } & \text { book.DET.ACC } \\ \text { 'It seemed to the judges that a woman had written the book.' } & \end{array}$

\footnotetext{
${ }^{6}$ The third option, so called lexical case, idiosyncratically assigned by individual lexical items, will not concern us here.
} 
(Preminger 2011: 174)

As we move away from more familiar languages, our understanding of case becomes less clear, and the distinction between structural and inherent case less reliable. Some researchers tend to impose this distinction from "above", by analogy with more familiar languages, and then form expectations based on those familiar languages. Another problem in the identification of case types in less studied languages arises when we simply do not have the familiar tools: many languages lack the sort of raising we find in Icelandic, or do not have nominalizations of the English type, leaving us without triedand-true diagnostics. Such difficulties have led some researchers to question the entire concept of two types of case assignment and call for its abandonment (Alsina 2001).

Is there any evidence from heritage languages for or against the two major types of case assignment, structural and inherent? ${ }^{7}$ To answer this question, we will start with two better-known languages: Russian and Spanish.

In Russian, as in English, the nominative and accusative are identified as structural cases, independent of theta-marking. Russian is not a pro-drop language, so the nominative is very common. ${ }^{8}$

(11)a. žil-byl krokodil

lived-was crocodile.NOM

'There lived a crocodile.'

b. Vanja zastrelil krokodil-a

Vanya.NOM shot crocodile-ACC

\footnotetext{
${ }^{7}$ In what follows, we will continue to use the traditional terminology, but what matters most is the actual distinction between the case types, not their names.

${ }^{8}$ For a comprehensive overview of the Russian case system, see Bailyn (2011: Part II).
} 
'Vanya shot the crocodile.'

The accusative is the case of the direct object; it has a distinct form for animates, as shown in (9b). With inanimates, however, the accusative and the nominative have the same form (see (11), the word for 'gift'). This is important for some of our discussion below.

The dative is considered an inherent case, and it occurs on the subject in experiencer constructions, (10), or on goal/recipient objects, (11). For a syntactic analysis of Russian datives, see Moore \& Perlmutter (2000), Sigurðsson (2002) and references therein.
Krokodil-u
bylo
grustno

crocodile-DAT

Was.PST.N Sad.N

'The crocodile was sad.'
papa
prines
Van-e
podarok

Dad.NOM brought

Vanya-DAT gift.ACC

'Dad brought Vanya a gift.'

The genitive is an inherent case assigned under negation (Pesetsky 1982) and in nominalizations, as in (12).

(14)
sobaka žen-y
general-a
dog wife-GEN general-GEN
'the general's wife's dog'

\footnotetext{
Russian also has a rich system of prepositions, all assigning inherent cases (Bailyn 2011: Part II and references therein), which we will not review here.
} 
Turning now to the production of Russian case forms by heritage speakers, we notice several clear asymmetries. The three cases that are most often left out (omission) are the accusative, the dative of the subject, and the genitive.

The nominative replaces those cases which are selected by prepositional head (dative, instrumental, locative, prepositional), which explains the high rate of its overgeneralization. It is probably more accurate to treat this phenomenon not as the overgeneralization of the nominative per se but as the extensive use of the unmarked case; general, unmarked case accounts for the bulk of object forms (replacing the accusative). The same change, from differential object marking with $a$ to an unmarked object case, is observed in Heritage Spanish (Montrul 2004, Montrul \& Bowles, 2009, Montrul \& Sánchez-Walker, in press).

The accusative is another case that exhibits overgeneralization. This overgeneralization is systematic; the accusative is regularly used as the case of the indirect object (goal/recipient) in place of the dative (see also Polinsky 2000, 2006). Thus, sentences like (11) above get produced in the following way:

$\begin{array}{llll}\text { papa } & \text { prines } & \text { Van-ju } & \text { podarok } \\ \text { Dad.UNMARKED } & \text { brought } & \text { Vanya-“ACC” gift.UNMARKED }\end{array}$

'Dad brought Vanya a gift.'

More proficient speakers retain the recipient/goal dative, while speakers with lower proficiency use the accusative. While morphological encoding varies, the grammar retains the special status of the indirect object case. By hypothesis, this is due to its nature as an inherent case. One could ask, however, why the dative experiencer is not retained; we would like to suggest that it is replaced with the nominative case by analogy with 
nominative subjects. A similar change is observed in Heritage Spanish: the inherent subject dative is replaced by the nominative, and the dative goal/recipient is retained (Montrul \& Bowles 2009, 2010).

The genitive of negation is on the wane even in baseline Russian (Comrie et al. 1996), so its presence in Heritage Russian is negligible; the bulk of genitive omissions comes from nominal expressions such as (14) which have an unmarked prenominal possessor:

$\begin{array}{ll}\text { [[general } & \text { [žena]] [sobaka]] } \\ \text { general } & \text { wife } \operatorname{dog}\end{array}$

Intended: 'the general's wife's dog' The inherent cases assigned by non-verbal heads (prepositions) are replaced by the general unmarked case ( nominative); however, the prepositional heads themselves are well-preserved (see Polinsky 2000; 2006 for details).

Table 1 summarizes the numerical data on the changes in heritage Russian, based on a number of investigations conducted by one of the authors of this article.

\begin{tabular}{lrrr} 
& suppliance & \multicolumn{1}{c}{ Omission } & overgeneralization \\
NOM & 94.6 & 0 & 63 \\
ACC & 46.3 & 35.2 & 18.8 \\
DAT exp & 43.7 & 32.6 & 0 \\
DAT goal & 58.7 & 18.3 & 8.3 \\
GEN & 53.6 & 30.7 & 2
\end{tabular}

Table 1. Mean percentages of incorrect case use in Heritage Russian production data (82 subjects, all English-dominant, avg. age 21.5) 
The data indicate the following trends: subjects all receive a uniform unmarked case, the accusative is lost, and the inherent case assigned by a verbal head (dative) is retained better than the inherent cases assigned by non-verbal heads.

At this juncture, we can try to explain these changes in two ways. The first approach distinguishes cases that occur in alternation with other cases and unique cases. Case forms which occur in alternation with some other case forms get replaced, typically by the unmarked form: this would account for the replacement of the dative subject by the nominative (subjects get encoded by these two cases but the nominative is much more common) and for the replacement of the accusative by the nominative (the unmarked case), which should be facilitated by the syncretism of nominative and accusative with inanimates. The dative of the indirect object does not appear in alternation with any other forms and it gets retained, either with the same marking as in the baseline, or marked as the baseline accusative. However, this approach fails to account for the loss of the genitive of possession and for the loss of prepositional cases (which all have unique marking).

The alternative is to connect the loss or retention of case with theta-roles. Those case forms that have a clear connection to a particular theta-role get expressed and recognized. This alternative equally fails to account for the loss of the dative subject (which is reanalyzed by analogy with the nominative subject). The prepositional case forms can considered marked by the preposition itself, which makes the use of an overtly marked case redundant.

Whichever account we pursue, the production data may be due to performance limitations and should therefore be checked against comprehension data. The following 
results show the ratings of case omission for Russian accusative, dative (experiencer and goal/recipient), and genitive of possession. The listeners heard an unmarked case and had to rate the acceptability of the sentence containing it using a 1-7 scale (1=lowest, $7=$ highest $)^{9}$

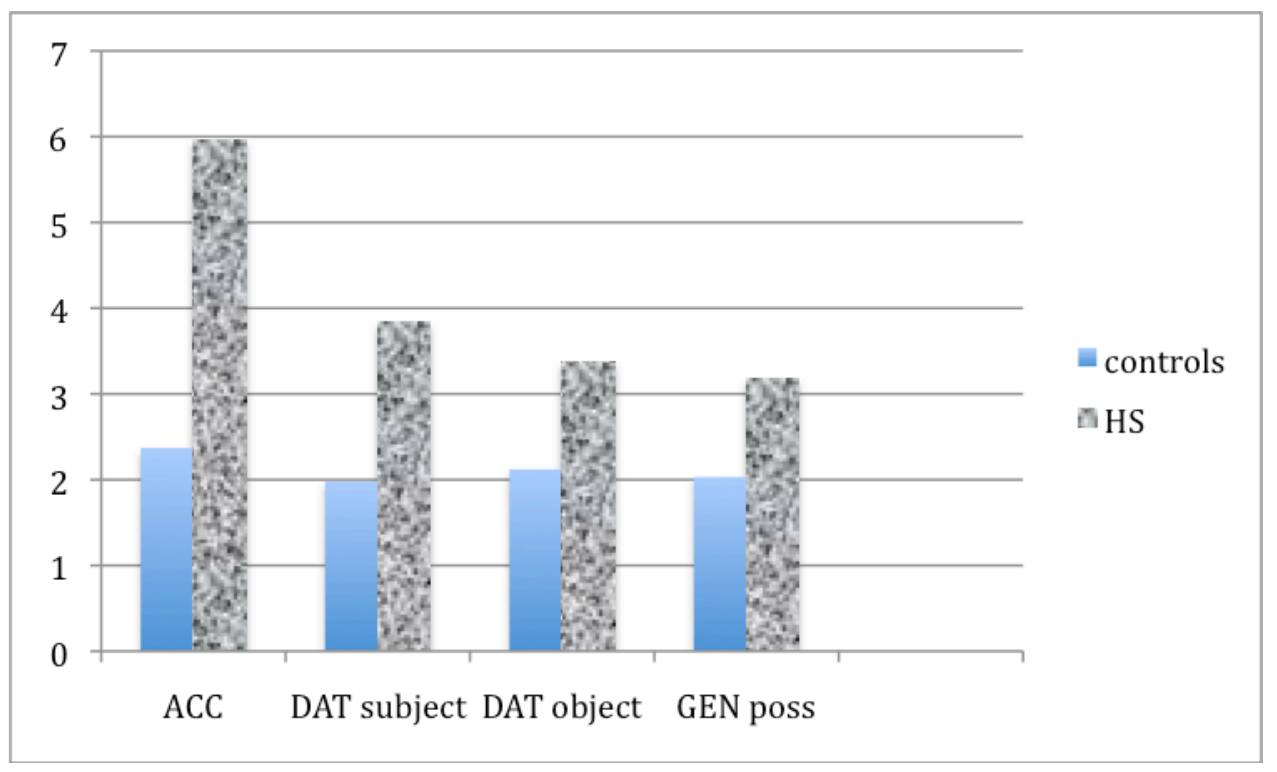

Figure 1. Russian case mismatches, comprehension (20 native speaker controls, 23 heritage speakers (HS); age matched, avg. age 26; 1-7 scale)

These results show, in a much clearer way than the production data, that the heritage group makes a clear distinction between the accusative case on the one hand and all the other cases on the other. This distinction in comprehension is actually much crisper and supports the categorical distinction between the accusative as a structural case and the other cases as inherent. This distinction also supports the approach to case changes

\footnotetext{
${ }^{9}$ Since the nominative is an unmarked case there is no comparable way of assessing its mismatch.
} 
framed in terms of inherent/structural case rather than in terms of case alternations. The tentative generalization we can draw on the basis of these data is as follows:

(17) In a heritage language, STRUCTURAL CASE of the baseline is replaced by an unmarked case, whereas INHERENT CASE is maintained (although its morphological exponent may change compared to the baseline).

Now that we have established this generalization, let us apply it to the instances where the primary data have not been conclusive in establishing the status of a particular case as structural or inherent. The case we will consider is ergative: the case of the transitive subject, which is in contrast to the absolutive case, encoding the intransitive subject and the object of a transitive verb. Compare in Avar, a language of the Nakh-Dagestanian family spoken in the Caucasus:

a. was-as šiša b-ek-ana boy-ERG bottle.ABS III-break-PST

'The boy broke a/the bottle.'

b. was ruðowe Ø-ani-la

boy.ABS home I-go-PST

'The boy went home.'

The status of the ergative case has been the subject of much debate. A number of researchers identify it as an inherent case, assigned by the highest transitive $v$ head in the 
structure (cf. Butt \& King 2004; Woolford 2006 and references therein; Legate 2008, a.o.). The main arguments for treating ergative as an inherent case are twofold: it is assigned by a verb, not by a higher functional projection, and it is often though not always associated with the thematic role Agent, which suggests theta-marking. Scholars that treat the ergative as a structural case do so for the following reasons: it is not tightly linked to a particular theta role, it can be shown to be licensed by a functional projection (e.g., VoiceP) above the VP, and it does not get preserved under raising (Ura 2000). In particular, Davison $(1999,2000,2001)$ argues that the Hindi ergative is structural and shows that it is licensed in counterfactual constructions regardless of thematic role and the argument structure of the licensing verb.

Assuming case alternations, we would expect that either the ergative would be replaced by the absolutive or the absolutive would be replaced by the ergative (both encode subjects and the direction of change may be hard to predict).

Assuming the generalization established in (15) if the ergative is an inherent case, we expect it to be well preserved in the resulting heritage language. If however it is a structural case, it should meet the fate of the Russian and Spanish accusative and be erased, replaced by some (unmarked) case.

We will consider data from two heritage languages with morphological ergativity, Hindi and Avar. In Hindi, a split ergative language, the ergative is marked with a postposition $-n e$, and the accusative and dative are marked by the homophonous postposition -ko. Compare:
a. Mira-ne
ramesh-ko
dekh-aa.
Mira-ERG
Ramesh.M.SG-ACC
Saw-PERF.M.SG 
'Mira saw Ramesh.'

b. Mira-ko ajmal yaad aa-yaa

Mira-DAT Ajmal.M.SG memory.F.SG come- PERF.M.SG

'Mira remembered Ajmal.'

In their productions, heritage speakers of Hindi omit - ne marking with ergative subjects at a rate of $36 \%$, whereas their omission of $-k o$ with dative objects is about $15 \%$ (Montrul et al. 2012). Omissions of the dative for indirect objects were not attested in production $(0 \%)$, and for dative subjects omissions were only $7 \%$.

The differential acceptance of case marker omission was also evident in a bimodal acceptability judgment task, with stimulus presentation in auditory and visual modality.. The same group of Hindi heritage speakers rated sentences with $-n e$ and -ko omission as significantly more acceptable than the baseline of fully fluent speakers of Hindi. Within the heritage group, the mean acceptability ratings of case omission were as follows (where 1 = unacceptable and 4 = perfectly acceptable): 2.12 for ergatives, 2.35 for dative subjects, 2.5 for specific direct objects, but only 1.56 for indirect objects, and the differences were significant (Montrul et al. 2012). Thus, we see a big divide between tolerance for the omission of the ergative, accusative, and dative subject marker vs. sensitivity to the omission of dative indirect object marking.

The significant erosion of the Hindi ergative suggests that it is a structural case; it patterns the same way as the accusative in Russian or Spanish. Note the contrast to the structural dative, which is well preserved, particularly in marking the indirect object. As in Spanish, dative subjects seem more affected than indirect objects. This suggests that changes in the case system are also sensitive to the grammatical function of the relevant 
DP, and subjects may have their own trajectory, equally influenced by case licensing and their prominent role in the predication relation.

Let us now turn to Avar. Avar has about 750 thousand speakers, and a significant number of younger urban speakers are dominant in Russian and sometimes have just a passing knowledge of their home language, despite having been exposed to it from birth.

In comprehension, we compared the interaction of three case forms: absolutive, dative, and ergative. We replaced each form by the other two case forms; for example, instead of the ergative, our subjects heard a dative in one set of stimuli, and the absolutive in the other set. They were asked to rate the acceptability of sentences containing mismatched form on a 1-7 scale ( $1=$ lowest, $7=$ highest). The data are summarized in Table 2.

\begin{tabular}{|l|l|l|l|l|}
\hline & $\begin{array}{l}\text { Mismatched } \\
\text { ERG }\end{array}$ & $\begin{array}{l}\text { Mismatched } \\
\text { DAT }\end{array}$ & $\begin{array}{l}\text { Mismatched } \\
\text { ABS object }\end{array}$ & $\begin{array}{l}\text { Mismatched } \\
\text { ABS subject }\end{array}$ \\
\hline ERG & & $1.15 / 1.87$ & $1.73 / 3.65$ & $1.18 / 3.78$ \\
\hline DAT & $1.32 / 2.11$ & & $1.25 / 2.56$ & $1.37 / 2.94$ \\
\hline ABS & $1.07 / 1.16$ & $1.14 / 1.35$ & & \\
\hline omission & $1.13 / 1.43$ & $1.18 / 1.48$ & $1.26 / 3.78$ & $1.33 / 3.29$ \\
\hline
\end{tabular}

Table 2. Ratings of Avar sentences containing case mismatches (first number controls/second number heritage speakers, 12 controls/ 15 heritage speakers, age matched, avg. age $34 ; 1-7$ scale)

The difference between the baseline speakers and the heritage speakers is quite clear: the controls are equally sensitive to all the mismatches in case whereas the heritage speakers show an intriguing differentiation. In contrast to Hindi, the Avar ergative and dative are 
well preserved in heritage speakers' mental representation, as reflected in their relatively low ratings. This in turn indicates that the ergative in Avar is an inherent case. Significant changes in the use of the absolutive, reflected in the higher ratings of its misuse, suggest that it is a pure structural case.

Where does this leave us with respect to the status of the ergative crosslinguistically? We can now hypothesize that ergative can be either a structural case, as in Hindi, or an inherent case, as in Avar. The ongoing debate between theoreticians of ergativity therefore reflects a reality that is more complex than what we have previously acknowledged.

If parametric variation in ergative case assignment is an empirical reality (and of course, it will need to be tested with more than just two languages) we have to return to linguistic theory and determine what properties of language design correlate with structural vs. inherent ergative case. The contribution of heritage language study is clear: it allows us to ask and answer questions which would not have been raised otherwise.

\subsection{Interface phenomena}

The model of language representation in heritage speakers builds on the following assumption: heritage speakers control the rules of particular modules (e.g., narrow syntax, phonology) but experience difficulty at the interfaces between modules. The Interface Hypothesis (Sorace 2011, 2012, Sorace \& Serratrice 2007) states that interface difficulty is what accounts for the attrition of null pronominalization in near-native speakers. To further test this hypothesis, one must apply it to new populations, including heritage speakers (see Montrul \& Polinsky 2011), as well as to phenomena beyond null pronominalization. 
In this section, we present and analyze two interface phenomena: aspectual computation and the syntax-phonology/morphology interface. Our conclusions suggest that heritage speakers indeed experience additional problems when they have to compute interface properties.

\subsubsection{Aspect}

Laleko $(2008,2010)$ advances an account of grammatical aspect as a category representative of interface effects. She investigates the model of Slavic aspect, notorious for its difficulty for L1 and L2 learners. On the lexico-syntactic level, Russian aspectual distinctions are ostensibly tied to lexical aspect, i.e., telicity of the verbal predicate. For verbs that are inherently specified as telic or atelic, the default aspectual value at this level is calculated based on the semantic properties of the verb. In the absence of such a specification on the verbal root itself, compositional telicity of the verbal phrase, including the nominal argument, has the potential of contributing to the resulting aspectual value of the VP (Laleko 2008, and references therein). On the sentential level, the contribution of telicity may be overridden by aspectual operators, such as habitual and progressive imperfectivizers, which license imperfective aspectual marking with telic eventualities. Telicity may also be overridden by delimiting perfectivizing prefixes such as $p o-$ and $z a-$, which supply an external boundary to lexically unbounded eventualities. In the absence of sentential aspectual triggers, the default lexical aspect projects directly onto the sentential level. Finally, operating at the highest level of syntactic structure, which interfaces with discourse-pragmatics, are pragmatically-conditioned aspectual triggers. These triggers are sensitive to external contextual factors in mediating aspectual 
meanings. Here, aspectual contrasts reflect such notions as the thematicity of the predicate and the illocutionary force of the utterance. Thus, even in the absence of atelic interpretations of the verbal phrase at the lexical level or imperfective operators at the sentential level, Russian verbs may receive imperfective marking for pragmatic reasons. For example, imperfective marking may be used to indicate that the speaker is merely reporting some fact about a particular event, without regard to its completion, or to implicate that the result of the action denoted by the predicate has been annulled. Availability of such pragmatically-conditioned functions of the imperfective in Russian produces aspectual competition, a situation in which both aspectual forms are grammatically possible. The competition is successfully resolved in favor of the imperfective aspect in the presence of the relevant contextual triggers.

Data from monolingual speakers of Russian (Laleko 2010) are fully consistent with the model outlined above. In contrast, her data from advanced heritage speakers of Russian reveal a significant reduction of the pragmatically-conditioned functions of the imperfective aspect. When compared with baseline controls, heritage speakers exhibit lower acceptability rates for imperfective forms with completed events, even in the presence of contextual discourse-pragmatic triggers of imperfectivity. Further, heritage speakers are significantly less accurate in their interpretations of the annulled result implicature. Despite these differences, heritage speakers exhibit no overt grammatical errors with aspectual morphology in production. In accounting for the observed findings, Laleko (2010) argues that the three levels of aspectual structure - lexical, sentential, and discourse-pragmatic - are affected selectively in heritage language acquisition. The restructuring of aspect in advanced heritage grammars affects the C-domain: the highest 
level of sentential structure, a domain in which syntactic information is mapped onto discourse-pragmatic knowledge. As a result, the privative (single-valued) aspectual opposition of baseline Russian, in which the imperfective aspect is the unmarked member with a wider contextual distribution, undergoes a shift to an opposition of the binary type. This shift results in a representation of the contrast between perfective and imperfective in terms of plus or minus feature values. As a result, the distribution of aspectual forms is determined solely by the grammar, without any recourse to the interface, discourse-based features.

This type of reorganization suggests a covert restructuring of the aspectual system, because the disintegration of the aspectual system within the C-domain is manifested in infelicity rather than strict ungrammaticality. As a consequence, highly proficient heritage speakers continue to appear target-like in production even without the complete mastery of the intricate contextual uses of the Russian imperfective; they rely on grammatical cues instead.

Laleko’s (2010) model of aspect in Russian makes further predictions with respect to the directionality of aspectual restructuring across the sectors of the heritage continuum. While advanced heritage speakers seem to exhibit sensitivity to phenomena mediated in the C-domain (besides aspect, other difficulties in this category include apparent optionality with null and overt subjects and infelicitous use of overt determiners), heritage speakers at the lower level of the proficiency continuum are predicted to diverge from the baseline norm not only on the highest level of aspectual structure interfacing with discourse-pragmatics, but also on the intermediate level of sentential aspect, where grammatical aspectual triggers operate. Thus, we expect that 
lower proficiency heritage speakers may not be consistently sensitive to sentential aspectual operators, paying more attention to the default lexical aspect of the predicate. Consistent with these predictions, existing production data from low-proficiency heritage speakers of Russian, such as the naturally-occurring examples provided in Polinsky (2006, 2008c), reveal multiple instances of perfective aspectual forms occurring in the presence of imperfectivizing sentential triggers, such as habitual adverbs, when predicates are lexically or compositionally telic.

The encoding of temporality is an important area of ongoing research within theoretical linguistics, and investigation of the expression of aspectual distinctions in heritage languages provides a unique opportunity for advancing current theories of temporality based on qualitatively new data.

\subsubsection{Syntax-morphology interface}

Other vulnerable domains in heritage languages can be found at the syntax-morphology and syntax-phonology interfaces. This vulnerability can be illustrated by data from Arabic; the case in point has to do with the reanalysis of the construct state in several varieties of heritage Arabic. In Afro-Asiatic languages, the construct state is the way to form a genitive construction with a semantically definite head noun (Ritter 1988, Borer 1996, Benmamoun 2000, Siloni 2001). The head noun is placed in the construct state, which lacks any overt definite marking (despite being semantically definite), and is often phonetically shortened. The modifying dependent expression is placed directly afterwards, and no other word can intervene between the two.

$$
\text { a. }\left[{ }_{D P}[D P[\text { kitaab-u }] \quad[\text { DP l-walad-i }]] \quad[\text { AP l-žadii-u }]\right]
$$




book-NOM the-boy-GEN the-new-GEN
HEAD NOUN, CONSTRUCT STATE DEPENDENT DP
'the boy's new book'
*1-kitaab-u 1-walad-i 1-žadii-u
the-book-NOMthe-boy-GEN the-new-GEN

In (18), the head of the construct state (kitaab) cannot be overtly marked for definiteness, hence the ungrammaticality of (18b). However, forms equivalent to (18b) represent exactly what we find in heritage Arabic speech (Albirini \& Benmamoun, in press): Arabic heritage speakers tend to attach the definiteness markers to both members of the construct state.

lamma Sihi mən n-noom, liPi žarra...

when awoke.3SG.M from the-sleep found.3SG.M jar

\section{l-žarra l-Pazaaz}

the-jar the-glass

'When he woke up, he found a jar...the jar of the glass.' (Heritage Palestinian

Arabic)

$\begin{array}{ccc}\text { huwwa } & \text { raahit } \text { l-beit } & \text { r-ra?iis } \\ \text { he } & \text { went the-house } & \text { the-president }\end{array}$

'He went to the house of the president [king]' (Heritage Egyptian Arabic) 
In (19) and (20), the heads of the construct state, žarra and beit, carry the definiteness marker, which is not possible in the baseline. In standard speech, the members of the construct state form a single prosodic unit, which may explain why the definiteness marker is generated only once (on the assumption that there should be one marker per prosodic unit). It seems that heritage speakers do not treat the construct state as a single prosodic unit, and this is what allows them to double mark it. This divergence from the baseline may have to do with a failure to compute the interface level between syntax and PF, where the formation of the construct state ostensibly takes place (Benmamoun 2000: $141-143)^{10}$

Generalizing from this result, we expect that heritage speakers would have difficulty with operations that involve computation across more than one grammatical component, for example, across syntax and morphology. Such interface operations require knowledge of the principles and constraints operating on both components, together with the ways in which they map onto each other.

Interface effects may also underlie the nonstandard behavior in the context of agreement and coordination in heritage Arabic speech (Albirini et al. 2011).

$\begin{array}{lllll}\text { el-walad } & \text { wi-l-kalb } & \text { naayem } & \text { Sala } & \text { es-sriir } \\ \text { the-boy } & \text { and-the-dog } & \text { sleep.3SG.M } & \text { on } & \text { the-bed }\end{array}$

'The boy and the dog are sleeping on the bed.' (Heritage Egyptian Arabic)

\footnotetext{
${ }^{10}$ Alternatively, it is possible that the first member of the Construct State inherits the definiteness feature from the second member and that this feature inheritance mechanism is missing or has been lost in heritage Arabic.
} 
(21) displays closest conjunct agreement, with the verb agreeing with the DP 'dog', and not the entire coordinate DP 'the boy and the dog'. Though Arabic is well known for its close conjunct agreement (cf. Aoun et al. 1994), it only arises in the VS order; thus, in the baseline, (21) would be incorrect. Rather, full agreement is expected with the predicate when it follows the conjoined subject, as in (22). Closest conjunct agreement, i.e., the pattern we see in (21), is available in the baseline only with the VS order, (23).

$\begin{array}{lllll}\text { el-walad } & \text { wi-l-kalb } & \text { naayem-en } & \text { Sala } & \text { es-sriir } \\ \text { the-boy } & \text { and-the-dog } & \text { sleep-3PL } & \text { on } & \text { the-bed }\end{array}$

'The boy and the dog are sleeping on the bed.'

$\begin{array}{lllll}\text { naayem } & \text { el-walad } & \text { wi-l-kalb } & \text { Sala } & \text { es-sriir } \\ \text { sleep.3SG.M } & \text { the-boy } & \text { and-the-dog } & \text { on } & \text { the-bed }\end{array}$

'The boy and the dog are sleeping on the bed.'

Closest conjunct agreement has received a number of theoretical analyses which we will not discuss in great detail here (see Aoun et al. 1994, Benmamoun et al. 2009, Bošković 2009, Bhatt \& Walkow in press for details). For our purposes, the crucial generalization is that the computation of closest conjunct agreement relies on the interaction between syntax and the morpho-phonological component of grammar. Heritage speakers may no longer control this interface in their grammars; as a result, they display close conjunct agreement in the SV order. This means that heritage speakers rely on adjacency to compute agreement with the coordinate noun phrase subject, forgoing the more complex interface constraints. If this hypothesis is correct, here may be another instance of the difficulty associated with mapping from syntax to the PF interface. The reason we are tentative in this conclusion is that so far it is based on production alone; it is important to 
further test the erosion of interface agreement constraints in the comprehension of heritage speakers of Arabic and Hebrew.

It is expected that linguistic phenomena that require the interface of more than one grammatical component to be more difficult to acquire or more vulnerable to attrite. Interface phenomena require access to two separate systems with overlapping but convergent primitives and principles and rule of combination. In addition, they require knowledge of how to map one component onto the other, no simple task in any framework we are familiar with. As is well known, the mapping is never perfect and distortions are usually expected but those distortion always try to remain as close to the optimal output as possible. Theories such as Optimality Theory and Distributed Morphology have elaborate mechanisms to account for output patterns that may depart from the expected pattern or that alter, albeit minimally, the input form.

\section{What determines the shape of heritage grammars?}

In the previous sections, we presented a catalog of phenomena, both from comprehension and production, that have been observed in heritage languages. It may be hard to draw significant conclusions based on such sparse data, but at the risk of sounding precipitous we would like to consider possible factors that play a role in shaping heritage grammars. We identify four factors that may play a role: incomplete acquisition, attrition over the lifespan, transfer from the dominant language, and changes in parental/community input. We will examine each of these factors in turn.

\subsection{Incomplete acquisition}


Heritage speakers are early bilinguals who learned their second (majority) language in childhood, either simultaneously with the heritage language, or after a short period of predominant exposure to and use of the minority language at home. A common pattern in simultaneous bilinguals is that as the child begins socialization in the majority language, the amount of input from and use in the minority language is reduced. Consequently, the child's competence in the heritage language begins to lag, such that the heritage language becomes, structurally and functionally, the weaker language. Developmental delays that start in childhood never eventually catch up, and as the heritage child becomes an adult, the eventual adult grammar does not reach native-like development.

A clear example of such incomplete attainment is the acquisition of the subjunctive in Spanish. Blake (1983) tested monolingual children in Mexico between the ages of 4 and 12 on their use of the subjunctive in different clauses. He found that between the ages of 5 and 8 , knowledge and use of the subjunctive in these children was in fluctuation; children did not show categorical knowledge of the Spanish subjunctive until after age 10 . Heritage speakers who receive less input at an earlier age and no schooling in the language never fully acquire all the uses and semantic nuances of the subjunctive, as reported in many studies (Martínez Mira 2009, Montrul 2009, Potowski et al. 2009, Silva-Corvalán 1994; see Silva-Corvalán 2003 for a longitudinal study documenting incomplete acquisition of the subjunctive and other verbal forms in bilingual children).

Incomplete acquisition occurs primarily in childhood due to input insufficient to develop the full L1 system. However, as we discuss next, incomplete acquisition and 
attrition in childhood are not mutually exclusive, as both could occur either simultaneously for different structures or sequentially; structures that were acquired at a certain age can be lost later on. Also, as discussed earlier, in some cases, incomplete acquisition can be exacerbated by structural changes in the output of first generation speakers, who are presumably the interlocutors and main source of input of the heritage speakers.

\subsection{Attrition}

Under normal circumstances, L1 attrition refers to the loss of linguistic skills in a bilingual environment. It implies that a given grammatical structure reached full development and mastery and was stable for a while before suffering weakening or being subsequently lost after several years of reduced input or language disuse. Thus, attrition is "the temporary or permanent loss of language ability as reflected in a speaker's performance or in his or her inability to make grammaticality judgments that would be consistent with native speaker monolinguals of the same age and stage of language development." (Seliger 1996: 616).

Attrition may occur during the first generation of immigration, according to de Bot (1991), affecting structural aspects of the L1 due either to language shift or to a change in the relative use of the L1. ${ }^{11}$ Attrition can also occur much earlier, having more dramatic effects on the integrity of the grammar. Recent research suggests that the extent of attrition is inversely related to the age of onset of bilingualism (Bylund 2009; Montrul 2008; Pallier 2007). Prepubescent children tend to lose their L1 productive skills more quickly and to a greater extent than people who moved as adults and whose L1 was fully

\footnotetext{
${ }^{11}$ Until recently, the vast majority of studies on linguistic attrition were done on older adults (Levine 2001, Schmid 2011), who obviously attained full linguistic competence before attrition began and who also show aging effects.
} 
developed upon migration (Ammerlaan 1996; Hulsen 2000). That is, the extent of attrition and severe language loss is more pronounced in children younger than 10 or 12 years old than in individuals who immigrated after puberty. And within childhood, language attrition, most typically referred to as incomplete L1 acquisition (Montrul, 2008; Polinsky, 1997, 2006), also tends to be more extensive in younger children than in older children (Montrul, 2008). Research has also shown that severed or interrupted input in childhood, as in international adoptees, leads to severe attrition including total language loss, whereas reduced input in childhood, as in heritage speakers, leads to partial attrition and incomplete acquisition (Montrul 2011).

There are two ways to tease apart incomplete acquisition and attrition in later childhood. The first strategy consists of conducting longitudinal or semi-longitudinal studies of children like the ones by Anderson (1999), Merino (1983) and Silva-Corvalán (2003), who were able to document the incremental accumulation of errors in agreement, case or gender marking, in their investigation of immigrant children who arrived in their new country around age $8 ; 0$ or older. Their results generally show a significant accumulation of errors which eventually leads to the loss of a baseline pattern. It is yet to be determined at which point such error accumulation can reach the point of no return.

The other strategy is to compare children and adult heritage speakers. A recent study by Polinsky (2011) on comprehension of relative clauses in Russian heritage speakers showed that the child heritage speakers performed at ceiling, just like agematched monolingual Russian children and fully competent adult Russian speakers. Meanwhile, the adult heritage speakers had significant problems with relative clauses as compared with the other three groups. This is an indication of attrition over the lifespan. 
Obviously the children had adult-like grammatical knowledge of relative clauses, but the adult speakers re-analyzed that grammatical knowledge into a new system, where all relative clauses were interpreted as subject relatives.

\subsection{Dominant language transfer?}

An important point of contact between heritage speakers and second language learners that does not come up in L1 acquisition is the interplay between the learner's first (heritage) language and the second (dominant) language. Language transfer, or the nature of that particular interplay, is a foundational issue in second language acquisition research: to what extent does the first language grammar play a role in shaping the developing second language grammar? The effects of native language on the acquisition of a second language in different levels of linguistic analysis (phonology, morphology, syntax, semantics, lexicon) have been extensively documented in the second language acquisition literature over the years (Odlin 1989; White 1989; Gass \& Selinker 1992; Schwartz \& Sprouse 1996; Jarvis 1998). A similar question arises in other language contact situations, including pidgin and creole genesis, where phenomena like lexical borrowings and so-called areal features are the well known consequences of language contact. Research on bilingualism and language contact (both at the social and psycholinguistic level) also suggests that the second language can encroach on the structure of the native language in systematic ways (Cook 2003, Pavlenko \& Jarvis 2002, Seliger 1996).

In examining the linguistic characteristics of heritage grammars, the first question that comes to mind is whether many of the "simplified" characteristics observed in the 
heritage languages could be due to transfer from the dominant majority language. One can easily entertain the possibility that nominal and verbal inflectional morphology in Spanish and Russian heritage speakers is eroded because the contact language in most of the heritage speakers tested to date is English, a language which does not mark gender in nouns or have rich tense/aspect and mood morphology. The same explanation goes for the overuse of overt subjects and the loss of semantically based case in Spanish and Russian, and as well as for the preference for SVO over topicalization. The reanalysis of definite articles as having only a specific and not a generic interpretation in Spanish could also follow from contact with English.

An obvious way to resolve this question over the source of simplified characteristics in heritage grammars is by testing heritage speakers whose majority language is typologically close to their heritage language (Spanish heritage speakers in Italy or Brazil, for example) or by comparing the effects of different dominant languages on one and the same heritage language.

A recent example of this type of work is J.-H. Kim's (2007) study of binding interpretations by Korean heritage speakers in the USA and China. The study tested knowledge of binding interpretations with local and long-distance anaphors in different syntactic contexts. In many respects, Chinese and Korean are more similar than Korean and English. As such, Korean heritage speakers in China were expected to be more accurate with long-distance binding and than the Korean heritage speakers in the US. Kim found that the two groups of Korean heritage speakers still had a marked preference for local binding, regardless of the contact language. If similar findings are replicated with other groups of heritage speakers in different language-contact contexts, then the 
effect of the L2 may turn out to be not as strong, or at least not the only factor involved, in shaping the incomplete grammars of heritage speakers.

\subsection{Incipient changes in the input}

A frequent question that has come up in understanding the source of the seemingly non-native abilities of heritage language speakers is whether the immigrant communities themselves speak an altogether different variety from that spoken in the country where the language is dominant. In other words, it is important to ascertain patterns of language maintenance or change in the variety used by the immigrant community. Another way to frame this question is whether the input that heritage speakers get from the older immigrant generation is already different from the baseline, and whether the first generation grammar shows any of the properties attested in the heritage language spoken by the second generation. This approach is typical of sociolinguistic studies (Otheguy \& Zentella 2012). If a property is not part of the register spoken to the heritage speakers, then it cannot be acquired. Rothman (2007) and Pires \& Rothman (2009) illustrate this fact with data from heritage speakers of Brazilian and European Portuguese. European and Brazilian Portuguese have inflected infinitives, but these are only used in written registers in Brazilian Portuguese. Their research shows that European Portuguese heritage speakers, who still hear inflected infinitives in the input, have inflected infinitives in their grammars. Brazilian Portuguese heritage speakers, who would only be exposed to inflected infinitives in written registers with which they lack familiarity, do not have knowledge of inflected infinitives. 
Montrul (2004) and Montrul \& Bowles (2009) have found incomplete acquisition of differential object marking in Spanish heritage speakers (see also section 3.5 above). Most recently, Montrul \& Sánchez-Walker (under review) tested this phenomenon in adult and child heritage speakers and first generation immigrants (whose language corresponds to the language spoken by the parents of the heritage speakers), as well as control groups of children, young adults and adults in Mexico. They found that the child and adult heritage speakers omitted differential object marking with animate and specific direct objects, but so did the first generation immigrants. In comparison, the native speakers tested in Mexico had very low rates of omission of this marker. This suggests that differential object marking underwent attrition in adults in first generation immigrants. And since these immigrant adults are the main source of input to the heritage speakers, non-target use of differential object marking can only be amplified in the language of heritage speakers.

In the case of differential object marking, the erosion of a personal is already present in the input, but the greater loss of the marking in second generation speakers could also be due to transfer from English (English does not mark animate, specific direct objects overtly). Thus, we see a situation where the two factors work in synch. There is no a priori way to tell which of the factors we considered in this section would outweigh the others: incomplete acquisition, attrition, transfer, or inherent properties of the input. Isolating each factor is crucial for a better understanding of language loss and change, and it may be achieved by expanding the empirical grounding of heritage studies. . Although the research methodologies applied to heritage speakers so far have followed traditions in sociolinguistics, first language acquisition, second language acquisition and 
field linguistics, the study of heritage speakers would benefit from other psycholinguistic methodologies neuroimaging and computational modeling to complement behavioral data.

\section{Conclusions}

Research on heritage languages brings together several related fields that have much to gain from working with and talking to each other: theoretical linguistics, with its emphasis on universal principles of language structure; experimental linguistics, especially the study of comprehension, which stands to gain a lot from working with readily available, populations; L1 acquisition, which can compare normal and arrested development; and L2 acquisition, which can compare heritage languages with both first and second languages.

Although we are only just beginning to understand how heritage languages are structured, the emerging patterns point to interesting differences between complete and incomplete first language acquisition. The defining characteristic of heritage speakers is exposure to the heritage language in childhood, typically in the home and heritage community context. From a language acquisition perspective, this means that heritage speakers are usually exposed to the language during the critical period, unlike late L2 learners who also display variability in ultimate attainment but are exposed to the second language after puberty. The standard assumption is that exposure to natural language during the critical period (before puberty) should allow one to develop native-like competence, but, as we have seen, heritage speakers do not develop uniform native-like competence in all modules of grammar. 
On a number of occasions throughout this paper, we emphasized that heritage languages are still an unchartered territory for theoretical linguistics, but we would like to conclude on an optimistic note, underscoring how much these languages have to offer linguistic theory. A parallel that immediately comes to mind is the study of creoles. Some forty years ago, creoles were the domain of specific language study or sociolinguistics, and theoretical linguists were reluctant to go near them. As soon as linguists recognized that creole phenomena speak directly to Plato's problem in language, creoles gained visibility in linguistic theorizing. Heritage languages add yet another piece to the puzzle of how a grammar can be acquired under conditions of reduced input and use of the language.

Just like children, heritage speakers offer us an opportunity to study a language unencumbered by too much irregularity, external factors, and non-structural confounds. Their grammar has the minimal scaffolding needed for a language to stand, and it has minimal design features. To continue with the architectural metaphor, a heritage language has structural, material, and functional design values, but very few aesthetic ones: it is minimalist architecture as compared to the baroque of a full-fledged language with a literary tradition and a revered norm. This makes heritage languages a desirable object of investigation, and we need to learn how to use them better to enrich the debate about the nature of the language faculty. 


\section{References}

Albirini, A. and E. Benmamoun. In press. Aspects of second language transfer in the oral production of Egyptian and Palestinian heritage speakers. International Journal of Blingualism.

Albirini, A., E. Benmamoun, A., and Saadah, E. 2011. Grammatical features of Egyptian and Palestinian Arabic Heritage Speakers' Oral Production. Studies in Second Language Acquisition, 33, 273- 303.

Albirini. A., E. Benmamoun, E., and B. Chakrani, B. In press. Gender and number agreement in the oral production of Arabic heritage speakers. Bilingualism: Language and Cognition.

Alsina, Alex. 2001. Is case another name for grammatical function? Evidence from object asymmetries. In Objects and other subjects: Grammatical functions, functional categories and configurationality, Davies, William D., \& Dubinsky, Stanley [Eds], 77-102. Dordrecht: Kluwer.

Ammerlaan, T. 1996. You get it a bit wobbly... Exploring bilingual lexical retrieval in the context of first language attrition. Ph.D. Diss., University of Nijmegen.

Anderson, R. 1999. Noun phrase gender agreement in language attrition. Preliminary results. Bilingual Research Journal 23, 318-337.

Aoun, Joseph, Elabbas Benmamoun, and Dominique Sportiche. 1994. Agreement and Conjunction in Some Varieties of Arabic. Linguistic Inquiry 25: 195-220.

Arkadiev, P., Yu. Lander, A. Letuchiy, N. Sumbatova, and Ya. Testelets. 2009. Vvedenie: Osnovnye svedeneija ob adygejskom jazyke. In Aspekty polisintetizma: Očerki po grammatike adygejskogo jazyka, P. Arkadie et al. [Eds.],17-120. Moscow: RGGU.

Au, T., Knightly, L, Jun, S. \& Oh, J. 2002. Overhearing a language during childhood. Psychological Science 13, 238-243.

Au, T., J. Oh, L. Knightly, S.-A.Jun, and L. Romo. 2008. Salvaging a childhood language. Journal of Memory and Language 58, 998-1011.

Bailyn, J. F. 2011. The syntax of Russian. Cambridge: Cambridge University Press.

Baker, M.C. 2003. Lexical categories: Verbs, nouns, and adjectives. Cambridge: Cambridge University Press.

Benmamoun, E. 2000. The feature Structure of Functional Categories. New YorkOxford: Oxford University Press.

Benmamoun, E., Bhatia, A., \& Polinsky, M. 2009. Closest Conjunct Agreement in Head Final Languages. Linguistic Variation Yearbook 9, 67-88.

Benmamoun, E. Albirini, A, Montrul, S, \& Saadah, E. In press. Arabic plurals and Root and Pattern Morphology in Palestinian and Egyptian heritage speakers. Linguistic Approaches to Bilingualism.

Bhatt, R. and M. Walkow. In press. Locating agreement in grammar: An argument from agreement in conjunctions. Natural Language and Linguistic Theory

Blake, R. 1983. Mood selection among Spanish-speaking children, ages 4 to 12. The Bilingual Review 10, 21-32. 
Bobaljik, J.D. 2008. Where's Phi? Agreement as a post-syntactic operation. In D. Harbour, D. Adger \& S. Béjar (eds.). Phi-Theory: Phi features across interfaces and modules, 295-328. Oxford: Oxford University Press.

Bobaljik, J. and P. Branigan. 2006. Eccentric agreement and multiple case-checking. In A. Johns et al. (eds.). Ergativity: Emerging issues ., 47-78. Dordrecht: Kluwer.

Bolonyai, A. 2007. (In)vulnerable agreement in incomplete bilingual L1 learners. The International Journal of Bilingualism 11, 3-21.

Borer, H. 1996. The construct in review. In J. Lecarme, J. Lowenstamm \& U. Shlonsky (eds.), Studies in Afroasiatic Grammar 30-61. The Hague: Holland Academic Graphics.

Borer, H. \& Wexler, K. 1987. The maturation of syntax. In T. Roeper \& E. Williams (eds), Paramter Setting, 123-172. Dordrecht: Reidel.

Bošković, Z. 2009. Unifying first and last conjunct agreement. Natural Language and Linguistic Theory 27, 455-496.

Bowers, J. 1993. The syntax of predication. Linguistic Inquiry 24, 591-646.

Butt, M. and T. Halloway King. 2004. The status of case. In V. Dayal \& A. Mahajan (eds.), Clause structure in South Asian languages, 153-198. Dordrecht: Kluwer.

Bylund, E. 2009. Maturational constraints and first language attrition. Language Learning 59, 687-715.

Caramazza, A., Capitani, E., Rey, A. \& Berndt, R.S. 2001. Agrammatic Broca's aphasia is not associated with a single pattern of comprehension performance. Brain \& Language 76, 158-184.

Carreira, M. and Kagan, O. 2011. The results of the National Heritage Language Survey: Implications for teaching, curriculum design, and professional development. Foreign Language Annals.

Chomsky, N. 1986. Knowledge of Language: Its Nature, Origin and Use. New York: Praeger.

Comrie, B., G. Stone \& M. Polinsky. 1996. The Russian language in the twentieth century. Oxford: Clarendon Press.

Cook, V. 2003. The Effects of the Second Language on the First. Clevedon, UK: Multilingual Matters.

Crain, S. \& M. Nakayama, M. 1987. Structure dependence in grammar formation. Language. 63, 522-543.

Crawford, J. 2012. Developmental perspectives on the acquisition of the passive. Ph.D. Diss, University of Connecticut, Storrs.

Dąbrowska, E. 1997. The LAD goes to school: A cautionary tale for nativists. Linguistics $35,735-766$.

Dabrowska, E. (2012). Different speakers, different grammars: Individual differences in native language attainment. Linguistic Approaches to Bilingualism 2, 2, 219-253.

Davison, A. 1999. Ergativity: Functional and formal issues. In M. Darnell et al (eds.) Functionalism and formalism in linguistics 1,. Amsterdam: John Benjamins.

Davison, A. 2000. Dependent structural case' as a consequence of VP structure. Texas Linguistics Forum 42.

Davison, Alice. 2001. Ergative case licensing in a split ergative language. In Anvita Abbi, R.S. Gupta \& Ayesha Kidwai (eds.) Linguistic structure and language dynamics in South Asia. Delhi: Motilal Banarsidaa, 291-307. 
de Bot, K. 1991. Language attrition, competence loss or performance loss. In Sprache und Politik, B. Spillner (eds.), 63-65. Frankfurt-New York: Peter Lang.

De Groot, C. 2005. The grammars of Hungarian outside Hungary from a linguistictypological perspective. In A. Fenyvesi (eds.). Hungarian language contact outside Hungary 351-370. Amsterdam: John Benjamins.

Delgado, M. R. 2009. Spanish heritage language socialization practices of a family of Mexican origin. $\mathrm{Ph}$. D. Disertation, University of Arizona.

Drai, D., Grodzinsky, Y. \& Zurif, E. 2001. Broca's aphasia is associated with a single pattern of comprehension performance. Brain \& Language 76, 185-192.

Drai, D., \& Y. Grodzinsky. 2006. A new empirical angle on the variability debate: Quantitative neurosyntactic analyses of a large data set from Broca's Aphasia. Brain \& Language 76(2), 117-128.

Fenson, L., P. S. Dale, J. S. Reznick, El. Bates, D. J. Thal, \& S. J. Pethick. 1994. Variability in early communicative development. Monographs of the Society for Research in Child Development. 59( 5).

Fenyvesi, A. 2000. The affectedness of the verbal complex in American Hungarian. In Anna Fenyvesi \& Klára Sándor, (eds.) Language contact and the verbal complex of Dutch and Hungarian: Working papers from the 1st Bilingual Language Use Theme Meeting of the Study Centre on Language Contact, November 11-13, 1999, Szeged, Hungary, 94-107. Szeged: JGyTF Press.

Ferguson, C. 1959. Diglossia. Word 15, 325-340.

Fox, D. \& Y. Grodzinsky. 1998. Children's passive: a view from the by-phrase. Linguistic Inquiry 29, 311-332

Gass, S. \& L. Selinker. 1992: Language Transfer in Language Learning. Amsterdam: John Benjamins.

Godson, L. 2003. Phonetics of language attrition: Vowel production and articulatory setting in the speech of Western Armenian heritage speakers. Ph.D. Diss., UCSD.

Godson, L. 2004. Vowel production in the speech of Western Armenian heritage speakers. Heritage Language Journal 2.

http://www.international.ucla.edu/languages/heritagelanguages/journal/article.asp?parenti $\mathrm{d}=14648$ (accessed 9 May 2012)

Green, G. \& Morgan, J. 2005. Why verb agreement is not the poster child for any formal principle. In S. Mufwene, E, Francis, \& R. Wheeler (eds.) Polymorphous linguistics: Jim McCawley's Legacy, 455-478. Cambridge: MIT Press.

Grosjean, F. 1998. Studying bilinguals. Methodological and conceptual issues. Bilingualism: Language and Cognition 1, 131-149.

Håkansson, G. 1995. Syntax and morphology in language attrition. A study of five bilingual expatriate Swedes. International Journal of Applied Linguistics 5, 153171.

Haugen, E.I. 1987. Language planning. In H. Ammon, N. Dittmar J. Mattheier (eds.) Sociolinguistics, I, 626 - 637. Berlin: Walter de Gruyter.

Hayashibe, H. 1975. Word order and particles: A developmental study in Japanese. Descriptive and Applied Linguistics 8, 1-18.

Hornstein, N. 2009. A theory of syntax: Minimal operations and Universal Grammar. Cambridge: Cambridge University Press. 
Hulsen, M. 2000. Language loss and language processing. Three generations of Dutch migrants in New Zealand. Doctoral dissertation, University of Nijmegen, The Netherlands.

Jarvis, S. 1998. Conceptual transfer in the interlingual lexicon. Bloomington, IN: IULC Publications.

Kim, J-H. 2007. Binding interpretations in Korean heritage speakers and L2 learners Unpublished doctoral dissertation. Department of Linguistics, University of Illinois at Urbana-Champaign.

Kim, J-H, Montrul, S. \& Yoon, J. 2009. Binding interpretation of anaphors in Korean heritage speakers. Language Acquisition 16, 1, 3-35.

Kim, J-H., Montrul, S. \& Yoon, J. 2010. Dominant language influence in acquisition and attrition of binding: Interpretation of the Korean reflexive caki. Bilingualism: Language and Cognition 13, 73-84.

Knightly, L., Jun, S., Oh, J., \& Au, T. 2003. Production benefits of childhood overhearing. Journal of the Acoustic Society of America, 114, 465-474.

Kondo-Brown, K. 2009. Heritage background, motivation, and reading ability of upperlevel postsecondary students of Chinese, Japanese, and Korean. Reading in a Foreign Language 21, 179-197.

Laleko, O. 2008. Compositional Telicity and Heritage Russian Aspect. In Grosvald, Michael and Dionne Soares (eds.), Proceedings of the Thirty-Eighth Western Conference on Linguistics (WECOL) 19. UC Davis: Davis, CA. Pp. 150-160.

Laleko, O. 2010. The Syntax-Pragmatics Interface in Language Loss: Covert Restructuring of Aspect in Heritage Russian. Ph.D. Diss. University of Minnesota.

Lander, Yu. \& Ya. Testelets. 2006. Nouniness and specificity: Circassian and Wakashan. Paper presented at the conference "Universals and Particulars in Parts-of-Speech Systems", University of Amsterdam.

http://ivran.academia.edu/YuryLander/Talks/59041/_Yury_Lander_and_Yakov_Testelets Nouniness_and_specificity_Circassian_and_Wakashan

Lee, S.-̄H., M. Bong, \& M. Polinsky. 2012. Nouns and verbs in heritage Korean. Ms. Wellesley and Harvard University.

Legate, J. 2008. Morphological and abstract case. Linguistic Inquiry 39, 55-101.

Legate, J. \& C.Yang. 2002. Empirical Re-Assessment of Stimulus Poverty Arguments Linguistic Review 19, 151-162.

Levine, G. 2001. Incomplete First-Language Acquisition in the Immigrant Situation: Yiddish in the United States. (Linguistische Arbeiten 426.) Max Niemeyer Verlag.

Lynch, A. 1999. The subjunctive in Miami Cuban Spanish. Bilingualism, contact and language variability. Unpublished doctoral dissertation, University of Minnesota.

Mahajan, G. 2009. Ongoing deficits in heritage Hindi. Paper presented at the Third Annual Heritage Language Institute, Urbana Champaign, June 2009.

Martínez Mira, M. I. 2009. Spanish heritage speakers in the southwest: Factors contributing to the maintenance of the subjunctive in concessive clauses. Spanish in Context 6(1), 105-126.

McCarthy, J. 1979. Formal Problems in Semitic Phonology and Morphology. Ph.D. Dissertation. MIT. Cambrige. 
Meisel, J. 1997. The acquisition of the syntax of negation in French and German. Contrasting first and second language development. Second Language Research 13, 227-263.

Meisel, J. 2011. First and Second Language Acquisition. Cambridge University Press.

Merino, B. 1983. Language loss in bilingual Chicano children. Journal of Applied Developmental Psychology 4, 277-294.

Montrul, S. 2002. Incomplete acquisition and attrition of Spanish tense/aspect distinctions in adult bilinguals. Bilingualism: Language and Cognition 5, 39-68.

Montrul, S. 2004. Subject and object expression in Spanish heritage speakers. A case of morpho-syntactic convergence. Bilingualism: Language and Cognition 7, 125142.

Montrul, S. 2005. Second language acquisition and first language loss in adult early bilinguals: Exploring some differences and similarities. Second Language Research 21(3), 199-249.

Montrul, S. 2008. Incomplete Acquisition in Bilingualism. Re-examining the Age Factor. Amsterdam: John Benjamins.

Montrul, S. 2009. Incomplete acquisition of Tense-Aspect and Mood in Spanish heritage speakers: Special issue of The International Journal of Bilingualism 13(2), 239269.

Montrul, S. 2011. First language retention and attrition in an adult Guatemalan adoptee. Language, Interaction and Acquisition 2, 276-311.

Montrul, S. (2013). "Structural changes in three heritage languages." Invited talk. Radbound University Languages in Contact, De Leeuwenhorst, Noordwijkerhout, The Netherlands, January 23-25, 2013.

Montrul, S. \& Bowles, M. 2009. Back to basics: Differential Object Marking under incomplete acquisition in Spanish heritage speakers. Bilingualism: Language and Cognition, 12(3), 363-383.

Montrul, S. \& Bowles, M. 2010. Is grammar instruction beneficial for heritage language learners? Dative case marking in Spanish. The Heritage Language Journal 7(1), 47-73. http://www.heritagelanguages.org/

Montrul, S. \& Polinsky, M. 2011. Why Not Heritage Speakers? A response to Sorace. Linguistic Approaches to Bilingualism 1(1), 58-62.

Montrul, S. \& Ionin, T. 2010. Transfer effects in the interpretation of definite articles by Spanish heritage speakers. Bilingualism: Language and Cognition, 13(4), 449473.

Montrul, S. \& Ionin, T. 2012. Dominant language transfer in Spanish heritage speakers and L2 learners in the interpretation of definite articles. The Modern Language Journal 96(1), 70-94.

Montrul, S. \& Sánchez-Walker, N. (under review). Incomplete Acquisition of Differential Object Marking in Child and Adult Spanish Heritage Speakers. Special issue of Language Acquisition.

Montrul, S., Foote, R. \& Perpiñán, S. 2008a. Gender agreement in adult second language learners and Spanish heritage speakers: The effects of age and context of acquisition. Language Learning 58(3), 503-553.

Montrul, S., Foote, R., \& Perpiñán, S. 2008b. Knowledge of wh-movement in Spanish L2 learners and heritage speakers. In M. Almazán, J. Bruhn de Garavito \& E. 
Valenzuela (eds.), Selected Papers from the $8^{\text {th }}$ Hispanic Linguistics Symposium. Somerville, MA: Cascadilla Press.

Montrul, S., Bhatt, R., Bhatia, A. \& Girju, R. 2012. Erosion of Case and Agreement in Hindi Heritage Speakers. Linguistic Approaches to Bilingualism 2, 141-176.

Moore, J. \& D. Perlmutter. 2000. What Does it Take to be a Dative Subject? Natural Language and Linguistic Theory, 18, 373-416.

Murasugi, K. \& T. Kawamura. 2005. On the acquisition of scrambling in Japanese. In Joachim Sabel and Mamoru Saito (eds.), The Free Word Order Phenomenon: Its Syntactic Sources and Diversity, eds., 221-242. Berlin: Mouton de Gruyter.

O'Grady, W. 1997. Syntactic Development. Chicago: The University of Chicago Press.

O'Grady, W., M. Lee \& M. Choo. 2001. The acquisition of relative clauses by heritage and non-heritage learners of Korean as a second language: A comparative study. Journal of Korean Language Education 12, 283-94.

O'Grady, W., A. Schafer, J. Perla, O.-S. Lee, \& J. Wieting. 2009. A psycholinguistic tool for the assessment of language loss. Language Documentation and Conservation $3,100-12$.

Odlin , T.1989. Language Transfer: Cross-linguistic Influence in Language Learning. Cambridge: Cambridge University Press.

Oh, J., Jun, S., Knightly, L. \& Au, T. 2003. Holding on to childhood language memory. Cognition 86, B53-B64.

Otheguy, R. \& Zentella, A. C. 2012. Spanish in New York. Language Contact, Dialect Leveling and Structural Continuity. Oxford, UK: Oxford University Press.

Otsu, Y. 1994. Early acquisition of scrambling in Japanese. In Teun Hoekstra and Bonnie D. Schwartz (eds.), Language Acquisition Studies in Generative Grammar, 253264. Amsterdam: John Benjamins.

Pallier, C. 2007. Critical periods in language acquisition and language attrition. In Köpke, B., Schmid, M., Keijzer, M. \& S. Dosterst (eds.), Language Attrition. Theoretical Perspectives, 99-120. Amsterdam: John Benjamins.

Pakulak, E. and Neville, H. (2010). Proficiency differences in syntactic processing of monolingual native speakers indexed by event-related potentials. Journal of Cognitive Neuroscience 22(12), 2728-2529.

Pavlenko, A. \& Jarvis, S. 2002. Bidirectional transfer. Applied Linguistics, 23, 190-214.

Pereltsvaig, A. 2005. Aspect lost, aspect regained. In R. Slabakova and P. Kempchinski (eds.), Aspectual Inquiries, 369-395. Dordrecht: Kluwer.

Pesetsky, D. 1982. Paths and categories. Ph.D.Diss, MIT.

Pierce, A. 1992. Language Acquisition and Syntactic Theory: Comparative Analysis of French and English Child Grammars. Dordrecht: Kluwer.

Pires, A. \& Rothman, J. 2009. Disentangling Contributing Variables to Incomplete Acquisition Competence Outcomes: What Differences Across Brazilian and European Portuguese Heritage Speakers Tell Us. International Journal of Bilingualism 13(2), 211-238.

Polinsky, M. 1997. Cross-Linguistic Parallels in Language Loss. Southwest Journal of Linguistics 14/1-2: 87-123.

Polinsky, M. 2000. A Composite Linguistic Profile of a Speaker of Russian in the U.S." In O. Kagan \& B. Rifkin (eds.): The Learning and Teaching of Slavic Languages and Cultures: Toward the 21st Century, 437-65. Bloomington, IN: Slavica. 
Polinsky, M. 2005. World class distinctions in an incomplete grammar". In Dorid Ravid (ed.), Perspectives on language and language development. 423-438. Dordrecht: Kluwer.

Polinsky, M. 2006. Incomplete acquisition: American Russian. Journal of Slavic Linguistics 14:192-265.

Polinsky, M. 2008a. Heritage language narratives. In D. Brinton, O. Kagan \& S. Bauckus (eds), Heritage Language Education. A New Field Emerging, 149-164. New York: Routledge.

Polinsky, M. 2008b. Russian gender under incomplete acquisition. The Heritage

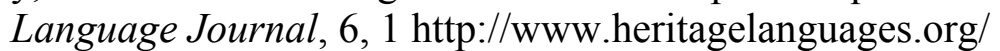

Polinsky, M. 2008c. Without aspect. In G. Corbett \& M. Noonan (eds.), Case and grammatical relations. Oxford: Oxford University Press.

Polinsky, M. 2009. What breaks in A- and A-bar chains under incomplete acquisition. Paper presented at $22^{\text {nd }}$ Annual CUNY Conference on Human Sentence Processing. University of California, Davis.

Polinsky, M. 2011. Reanalysis in adult heritage language: A case for attrition. Studies in Second Language Acquisition 33, 305-328.

Polinsky, M. \& O. Kagan. 2007. Heritage languages: In the 'wild' and in the classroom. Language and Linguistics Compass 1(5), 368-95.

Potowski, K., Jegerski, J. \& Morgan-Short, K. 2009. The effects of instruction on linguistic development in Spanish heritage language speakers. Language Learning 59, 537-579.

Preminger, O. 2011. Agreement as a fallible operation. Ph.D. Diss., MIT.

Ravid, D. \& Farah, R. 1999. Learning about noun plurals in early Palestinian Arabic. First Language, 19, 187-206.

Ritter, E. 1988. A head movement approach to construct state nominals. Linguistics 26, 909-929.

Rizzi, L. 1986. Null objects in Italian and the theory of pro. Linguistic Inquiry 17, 501557.

Rothman, J. 2007. Heritage speaker competence differences, language change, and input type: Inflected infinitives in heritage Brazilian Portuguese. The International Journal of Bilingualism 11, 359-389.

Sánchez-Walker, N. (2012). Comprehension of Subject and Object RElative Clauses in Spanish heritage speakers and L2 leraners of Spanish. PhD Qualifying paper, University of Illinois at Urbana-Champaign.

Schmid, M. 2011. Language Attrition. Cambridge University Press

Schwartz, B. 2004. Why child L2 acquisition? In J. Van Kampen \& S. Baauw (eds.), Proceedings of Generative Approaches to Language Acquisition 2003, .), 4766.Utrecht, The Netherlands: LOT Occasional Series.

Schwartz, B. \& Sprouse, R. 1996. L2 cognitive states and the full transfer/full access hypothesis. Second Language Research 12, 40-72.

Seliger, H. 1996. Primary language attrition in the context of bilingualism. In W. Ritchie \& T. Bhatia (eds.), Handbook of Second Language Acquisition, 605-625. New York: Academic Press.

Sells, P. 1987. Aspects of logophoricity. Linguistic Inquiry 18, 445-479. 
Serratrice L, Sorace Antonella, Filiaci Francesca, Baldo Michela. 2009. Bilingual children's sensitivity to specificity and genericity: Evidence from metalinguistic awareness. Bilingualism: Language and Cognition, 12(2), 239-257.

Sigurðsson, H. Á. 2002. To be an oblique subject: Russian vs. Icelandic. Natural Language and Linguistic Theory 20, 691-724.

Siloni, T. 2001. Construct states at the PF interface. Linguistic variation yearbook 1, 229-266.

Silva-Corvalán, C. 1994. Language Contact and Change: Spanish in Los Angeles. Oxford: Oxford University Press.

Silva-Corvalán, C. 2003. Linguistic consequences of reduced input in bilingual first language acquisition. In S. Montrul \& F. Ordóñez (eds.), Linguistic Theory and Language Development in Hispanic Languages, 375-397. Somerville, MA: Cascadilla Press.

Song, M., O’Grady, W., Cho, S. \& Lee, M. 1997. The learning and teaching of Korean in community schools. In Y.-H. Kim (eds.), Korean Language in America 2, 111127. American Association of Teachers of Korean.

Sorace, A. 2000. Differential effects of attrition in the L1 syntax of near-native L2 speakers. Proceedings of the $24^{\text {th }}$ Boston University Conference on Language Development, 719-725. Somerville, MA: Cascadilla Press.

Sorace, A. 2004. Native language attrition and developmental instability at the syntax-discourse interface: data, interpretations and methods. Bilingualism: Language and Cognition 7, 143-145.

Sorace, A. 2011. Pinning down the concept of "interface" in bilingualism. Linguistic Approaches to Bilingualism, 1-33.

Sorace, A. 2012. Pinning down the concept of "interface" in bilingsm: a reply to peer commentaries. Linguistic Approaches to Bilingualism 2, 209-216.

Sorace, A. \& Serratrice, L. 2009. Internal and external interfaces in bilingual language development: Beyond structural overlap. International Journal of Bilingualism 13, 195-210.

Thal, D., Bates, E., Zappia, M., \& Oroz, M. 1996. Ties between lexical and grammatical development: Evidence from early talkers. Journal of Child Language 23, 349368.

Thal, D., Bates, E., Goodman, J., \& Jahn-Samilo, J. 1997. Continuity of language abilities: An exploratory study of late- and early-talking toddlers. Developmental Neuropsychology 13, 293-274.

Tomasello, M. 2003. Constructing a language: A usage-based theory of language acquisition. Cambridge, MA: Harvard University Press.

Unsworth, S. 2005. Child L2, adult L2, child L1 differences and similarities. A study on the acquisition of object scrambling in Dutch. Doctoral dissertation. Utrecht Institute of Linguistics OTS, LOT, Netherlands Graduate School of Linguistics.

Unsworth, S., Argyri, F., Cornips, L., Hulk, A., Sorace, A. \& Tsimpli, I. (to appear). On the role of age of onset and input in early child bilingualism in Greek and Dutch. Applied Psycholinguistics.

Ura, H. 2000. Checking theory and grammatical functions in Universal Grammar. Oxford: Oxford University Press. 
Valdés, G. 2000. Introduction. Spanish for Native Speakers, Volume I. AATSP Professional Development Series Handbook for teachers K-16. New York, NY: Harcourt College.

Versteegh, K. 2001. The Arabic Language. Edinburgh: Edinburgh University Press Walters,K. 1996b. Diglossia, linguistic variation, and language change. In M. Eid (eds.), Perspectives on Arabic Linguistics VIII, 157-197. Philadelphia \& Amsterdam: John Benjamins.

White, L. 1989. Universal Grammar and Second Language Acquisition. Amsterdam: John Benjamins.

White, L. 2003. Second Language Acquisition and Universal Grammar. Cambridge: Cambridge University Press.

White, L. and F. Genesee. 1996. How native is near-native? The issue of ultimate attainment in adult second language acquisition. Second Language Research 12, $238-265$.

Williams, E. 1980. Predication. Linguistic Inquiry 11, 203-238.

Woolford, E. 2006. Lexical Case, Inherent Case, and Argument Structure. Linguistic Inquiry 37, 111-130.

Yoon, J.-M. 1989. Long-distance anaphors in Korean and their cross-linguistic implications. In Papers from the 25th Annual Meeting of the Chicago Linguistic Society, ed. Caroline Wiltshire, et al., 479-495. Chicago Linguistic Society.

Zaretsky, E. \& E. Bar-Shalom. 2010. Does reading in shallow L1 orthography slow attrition of language-specific morphological structures? Clinical Linguistics and Phonetics 24(4-5), 401-415. 